\title{
Persistent Activity in Prefrontal Cortex during Trace Eyelid Conditioning: Dissociating Responses That Reflect Cerebellar Output from Those That Do Not
}

\author{
Jennifer J. Siegel ${ }^{1}$ and Michael D. Mauk ${ }^{1,2}$ \\ ${ }^{1}$ Center for Learning and Memory and the 2Department of Neuroscience, University of Texas at Austin, Austin, Texas 78712
}

Persistent neural activity, responses that outlast the stimuli that evoke them, plays an important role in neural computations and possibly in processes, such as working memory. Recent studies suggest that trace eyelid conditioning, which involves a temporal gap between the conditioned and unconditioned stimuli (the trace interval), requires persistent neural activity in a region of medial prefrontal cortex (mPFC). This persistent activity, which could be conveyed to cerebellum via a pathway through pons, may engage the cerebellum and allow for the expression of conditioned responses. Given the substantial reciprocity observed among many brain regions, it is essential to demonstrate that persistent responses in $\mathrm{MPFC}$ neurons are not simply a reflection of cerebellar feedback to the forebrain, leaving open the possibility that such responses could serve as input to the cerebellum. This concern is highlighted by studies showing that hippocampal learning-related activity is abolished by cerebellar inactivation. We inactivated the cerebellum while recording single-unit activity from the $\mathrm{mPFC}$ of rabbits trained with a forebrain-dependent trace eyelid conditioning procedure. We report that, whereas the responses of cells that show an onset of increased spike activity during the trace interval were abolished by cerebellar inactivation, persistent responses that begin during the conditioned stimulus and persisted into the trace interval were unaffected. Therefore, conditioned stimulus-evoked persistent responses remain the strongest candidate input pattern to support the cerebellar expression of learned responses.

\section{Introduction}

It is important to determine not only the function of each brain system but also how brain systems interact. Given the ubiquitous presence of reciprocal connectivity in the brain, it is possible that some of the spike responses observed in a putatively upstream brain region could actually reflect feedback from a downstream structure. Trace eyelid conditioning provides an opportunity to study such interactions because the expression of learned responses depends on a pathway between the medial prefrontal cortex (mPFC) and cerebellum (Kronforst-Collins and Disterhoft, 1998; Takehara et al., 2003; Kalmbach et al., 2009), via the pons (Weible et al., 2007; Siegel et al., 2012). Trace conditioning involves paired presentations of a conditioned stimulus (CS) followed by an unconditioned stimulus (US), with a stimulus-free trace interval between CS offset and US onset. It had been generally assumed that the cerebellum can support learning only when there is temporal overlap between stimuli (Ito et al., 1982; Weiss and Disterhoft, 1996; Mauk and Donegan, 1997). A recent study directly confirmed this assumption using microstimulation of

Received March 22, 2013; revised Aug. 2, 2013; accepted Aug. 20, 2013.

Author contributions: J.J.S. and M.D.M. designed research; J.J.S. performed research; J.J.S. analyzed data; J.J.S. and M.D.M. wrote the paper.

This work was supported by Grants NIH MH74006 and MH46904 and the McKnight Foundation.

The authors declare no competing financial interests.

Correspondence should be addressed to Dr. Jennifer J. Siegel, Center for Learning \& Memory, University of Texas at Austin, 1 University Station Stop C7000, Austin, TX 78712-0805. E-mail: jenni@mail.clm.utexas.edu.

DOI:10.1523/JNEUROSCI.1238-13.2013

Copyright $\odot 2013$ the authors $\quad 0270-6474 / 13 / 3315272-13 \$ 15.00 / 0$ cerebellar inputs in place of the CS and demonstrating that animals could not learn unless cerebellar inputs were active within $300 \mathrm{~ms}$ of US onset (Kalmbach et al., 2009). Importantly, during trace conditioning, neurons in the mPFC respond to the CS with spike activity that persists into the trace interval to overlap (or nearly so) with the timing of the US (so-called "persistent" responses) (Takehara-Nishiuchi and Mcnaughton, 2008; Siegel et al., 2012). Regions of mPFC that show persistent activity project to pontine regions that also show persistent activity, supporting the hypothesis that the role of the $\mathrm{mPFC}$ in trace conditioning may be to provide the cerebellum with an input that overlaps with the US (Siegel et al., 2012). However, a second response type was also observed in the mPFC that overlaps with the timing of the US, which displayed increased activity during the trace interval (after CS offset) and appeared to be highly correlated with the animal's learned eyelid response (i.e., "trace interval" responses; see Fig. 1A) (Siegel et al., 2012).

We used reversible inactivation to block cerebellar output during trace eyelid conditioning while recording neurons in the mPFC to determine which spike response pattern (s) are independent of cerebellar output (i.e., do not reflect feedback) and therefore remain candidate sources of the input to the cerebellum necessary for the expression of learned responses. We found that persistent responses were spared by cerebellar inactivations that abolish learned behavioral responses, whereas trace interval responses were abolished along with learned behavior during inactivations. The data suggest that trace interval responses reflect feedback originating from the motor output pathway, whereas 
persistent responses are a consequence neither of cerebellar output nor the expression of the learned responses. We propose that an $\mathrm{mPFC}$ persistent response to the CS is the strongest candidate source of input to the cerebellum necessary for trace eyelid conditioning.

\section{Materials and Methods}

Subjects and surgical procedures. All surgical and experimental procedures were approved by the University of Texas at Austin Institutional Animal Care and Use Committee and were in accordance with the National Institutes of Health guidelines. Six New Zealand albino rabbits (males, $2.5-4 \mathrm{~kg}$ ) were implanted with infusion guide cannula targeting the anterior interpositus and a custom microdrive housing 18 independently moveable tetrodes targeting the region of mPFC that is necessary for trace eyelid conditioning (Kronforst-Collins and Disterhoft, 1998; Kalmbach et al., 2009). Each rabbit was prepared for sterile surgery by subcutaneous injection of ketamine $(45 \mathrm{mg} / \mathrm{kg})$ and acepromazine $(1.5$ $\mathrm{mg} / \mathrm{kg}$ ) and mounted in a specialized stereotaxic apparatus (with $\lambda 1.5$ $\mathrm{mm}$ below bregma). Surgical depth then maintained with $1-3 \%$ isoflurane. Microdrive tetrode bundles $(\sim 1.5 \mathrm{~mm}$ in diameter $)$ were positioned on the brain's surface over the right posterior mPFC (centered at $3.0 \mathrm{~mm}$ anterior to bregma and $1.5 \mathrm{~mm}$ lateral from the midline) and secured to the skull with skull screws and dental cement. In addition to recording electrodes, a single infusion guide cannula was implanted in each rabbit such that the tip was positioned $1.2 \mathrm{~mm}$ above the contralateral anterior interpositus nucleus $(0.7 \mathrm{~mm}$ anterior, $5 \mathrm{~mm}$ lateral, and $13.3 \mathrm{~mm}$ ventral to $\lambda$ ). Rabbits were also prepared with a head bolt fixed in dental cement over the anterior skull (to hold the eyelid detector during conditioning), and two stainless steel periorbital stimulating electrodes implanted subdurally just anterior and posterior to the upper eyelid contralateral to the mPFC microdrive and ipsilateral to the interpositus infusion guide cannula. Example histology regarding placements of cannula in the cerebellum and estimated single-unit recording sites in the $\mathrm{mPFC}$ are shown in Figures $1 B$ and 2. Each rabbit was given at least 1 week of recovery before training began.

Behavioral training and analysis. Rabbits were trained with a trace eyelid conditioning protocol as previously described (Siegel et al., 2012). Briefly, rabbits were gently restrained and placed in shielded, soundattenuating chambers. Daily training sessions were controlled by custom software and consisted of 12 blocks of 9 trials for a total of 108 trials per session, with the first trial of every block being a CS-only probe. Trials were presented at random intertrial intervals between 25 and $35 \mathrm{~s}$. Each trial consisted of a $500 \mathrm{~ms}$ CS (a $1.3 \mathrm{kHz}$ pure tone) with onset/offset rise/fall times of $5 \mathrm{~ms}$ to avoid audible onset and offset transients (clicks), followed by a $500 \mathrm{~ms}$ stimulus-free period (the trace interval) and terminated with a $50 \mathrm{~ms}$ train of current pulses ( $1 \mathrm{~ms}$ pulse width at $100 \mathrm{~Hz}$ ) delivered across the periorbital electrodes (the US). The US intensity was carefully adjusted for each rabbit to just above threshold for full eyelid closure (between 1 and $3 \mathrm{~mA}$ ). For each trial, beginning $200 \mathrm{~ms}$ before tone onset, the position of the external eyelid was measured for $2.5 \mathrm{~s}$ with an infrared emitter and collector assembly held in front of the eye and fixed to the head bolt. Eyelid responses recorded during training trials were digitized at $1 \mathrm{kHz}$ and stored for subsequent offline analyses. Before each training session, the eyelid detector was calibrated by measuring the voltage response produced by a full eyelid closure and defining that voltage change as $6.0 \mathrm{~mm}$ (the amplitude of a full eyelid closure in rabbit). A CR was defined as an eyelid closure that exceeded $0.3 \mathrm{~mm}$ between CS and US onsets. Trials with eyelid responses $>0.3 \mathrm{~mm}$ in the $200 \mathrm{~ms}$ before CS onset were excluded from behavioral and spike analyses (never $>5$ trials/session).

Cerebellar infusion procedure. Before infusions began, each rabbit was trained for at least two sessions beyond the session during which a standard criterion of eight conditioned responses in nine consecutive trials was met (Siegel et al., 2012). To reversibly inactivate the anterior interpositus, we infused a solution of $1 \mathrm{~mm}$ muscimol (Tocris Bioscience) dissolved in artificial CSF (in mM as follows: $119.0 \mathrm{NaCl}, 2.5 \mathrm{KCl}, 1.2$ $\mathrm{NaH}_{2} \mathrm{PO}_{4}, 26.0 \mathrm{NaHCO}_{3}, 2.0 \mathrm{CaCl}_{2}, 2.0 \mathrm{MgCl}_{2}, 10.0$ dextrose, 10.0 HEPES, pH adjusted to 7.35-7.4, and passed through a $2 \mu \mathrm{m}$ filter to sterilize). The solution was loaded into a Hamilton syringe fitted with tygon tubing and a sterile 1.2-mm-long 33-gauge infusion cannula. The syringe was mounted in an electric pump apparatus (Bioanalytical Systems, models MD-1001 and 1020) to allow for fine control over the rate of infusion.

For infusion sessions, rabbits first received either 3 blocks ( 7 sessions from 2 rabbits) or 6 blocks ( 14 sessions from 4 rabbits) of training to collect baseline single-unit activity. The training session was then paused and the infusion cannula inserted into the deep nuclei of the cerebellum (DCN) guide cannula. Muscimol was infused at a rate of $0.2 \mu \mathrm{l} / \mathrm{min}$ for $10 \mathrm{~min}(2 \mu \mathrm{l}$ total volume). The session was resumed $5 \mathrm{~min}$ after the completion of the infusion. An infusion was considered effective when the likelihood of CRs decreased $<50 \%$ for a given block, followed by $<15 \%$ CRs observed for all remaining blocks. Importantly, rabbits still showed unconditioned reflexive responses to the US (examples given in Figs. 3, 4, 5), and so the abolishment of CRs is likely the result of selective inactivation of the motor output pathway that drives the learned response, and not the result of a general disfacilitation (Pacheco-Calderón et al., 2012). Most rabbits showed an immediate effect upon resuming the session that lasted for the remainder of the session, whereas 2 rabbits ( 4 sessions) showed a delay in the onset of the effect (by 1-3 blocks) but showed a nearly complete effect thereafter. The behavioral results of infusion sessions were bimodal; infusion sessions that did not meet the above behavioral criteria as effective were not different from noninfusion session comparisons (see Results). Therefore, ineffective infusion sessions were included as controls ( 6 sessions from 4 rabbits) in addition to noninfusion sessions (taken the day before successful infusions; 14 sessions from 5 rabbits). For most rabbits in which effective inactivation was observed, at least 3 infusion sessions could be performed with successful results before the manipulation became ineffective, presumably because of the buildup of gliosis at the infusion site that prevented sufficient diffusion of the drug. However, one rabbit continued to be effective for 6 infusion sessions, until tetrodes had reached the ventral extent of the mPFC and no more data could be collected. We took advantage of this opportunity to infuse Alexa 594-conjugated dextran ( $1 \mu \mathrm{l}$ at $0.2 \mu \mathrm{l} / \mathrm{min}$; Invitrogen; 10,000 MW) to estimate the degree of diffusion.

Single-unit recordings. Neural activity was acquired during control and infusion sessions with a Digital Lynx system (Neuralynx). Tetrodes were constructed from polyimide-coated nichrome wire $(12 \mu \mathrm{m}$ diameter, Kanthal Palm Coast) and gold-plated to an impedance of $0.5-1.25 \mathrm{M} \Omega$ at $1 \mathrm{kHz}$. Signals were passed to a multichannel, unity-gain headstage, amplified and bandpass filtered between 600 and $6000 \mathrm{~Hz}$, and digitized at $32 \mathrm{kHz}$ for subsequent offline analysis. Neural data were synchronized with the presentation of training stimuli by triggering the Digital Lynx I/O port with the same TTL pulses used to trigger CS and US stimuli. The first noninfusion control sessions typically began 3 sessions after rabbits achieved asymptotic performance and were followed the next day by an infusion session. After the initial set of sessions, to ensure that a given neuron was not included more than once between infusion sessions, tetrodes were advanced a minimum of $160 \mu \mathrm{m}$ from the site of previous single-unit activity after each DCN infusion session (Siegel et al., 2012). Tetrodes were allowed to settle for $3 \mathrm{~d}$ to maximize recording stability and were adjusted minimally between the initial noninfusion recording session and the infusion session recorded on the following day, after which tetrodes with isolated single-unit activity were moved another 160 $\mu \mathrm{m}$ and the procedure repeated until infusions were no longer effective or until all tetrodes appeared to have reached the ventral extent of the mPFC. In short, rabbits received muscimol infusions no sooner than the fourth session of asymptotic performance and additional infusions approximately once per week until infusions were no longer effective $(n=$ $4)$ or until tetrodes had reached the ventral aspect of the $\operatorname{mPFC}(n=1$; typically 3 infusion sessions were possible, and in one case 6 were effective). Tetrodes in the lateral $\mathrm{mPFC}$ reached the ventral extent (the corpus callosum) well before more medial tetrodes (e.g., see Fig. 2), and so single-unit activity could only be recorded from the medial half of tetrodes for some sessions.

The activity of single units was isolated offline using interactive cluster-cutting software (WinClust; J. J. Knierim and M. D. Mauk, adapted from M. A. Wilson), as previously described (Siegel et al., 2012). 
A

Activity patterns observed during trace eyelid conditioning

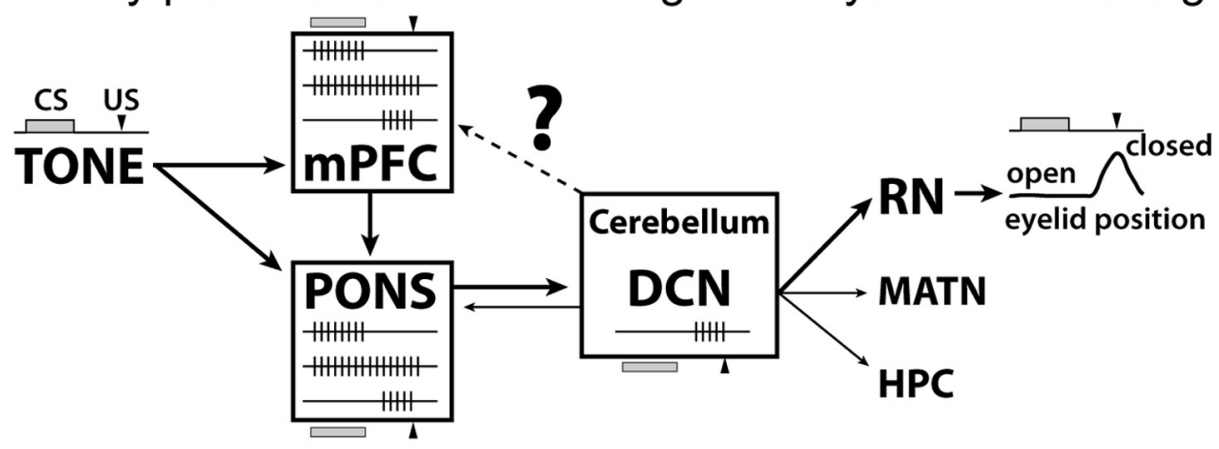

DCN inactivation during trace eyelid conditioning

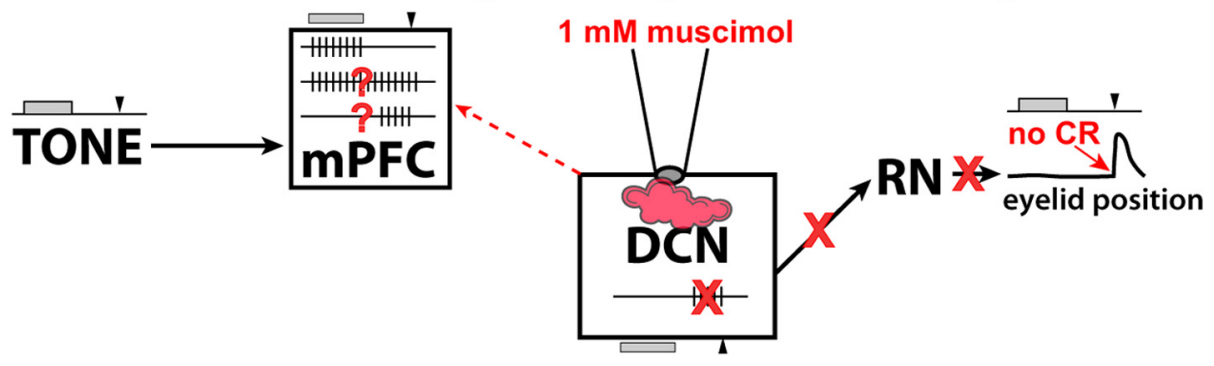

B
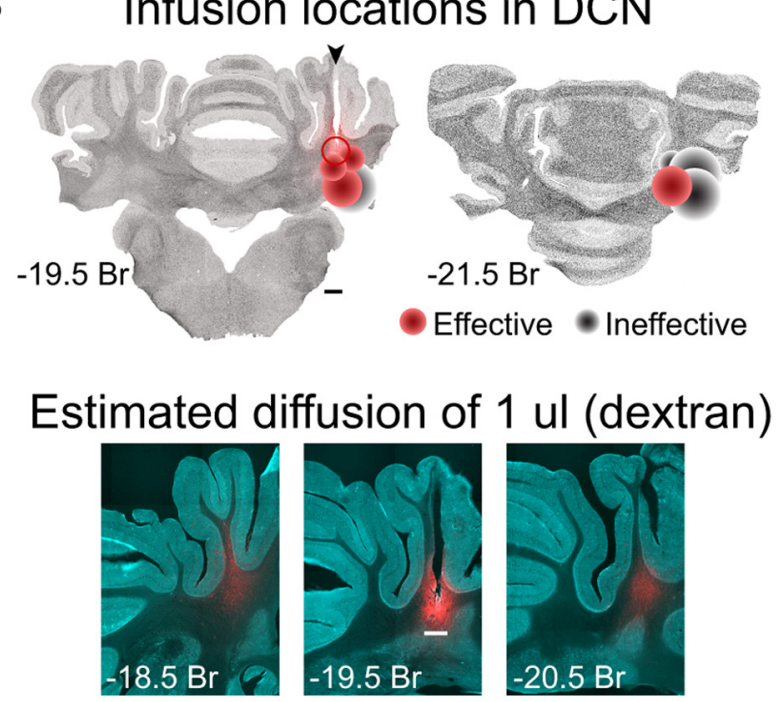

C Effective DCN inactivation abolishes trace CRs

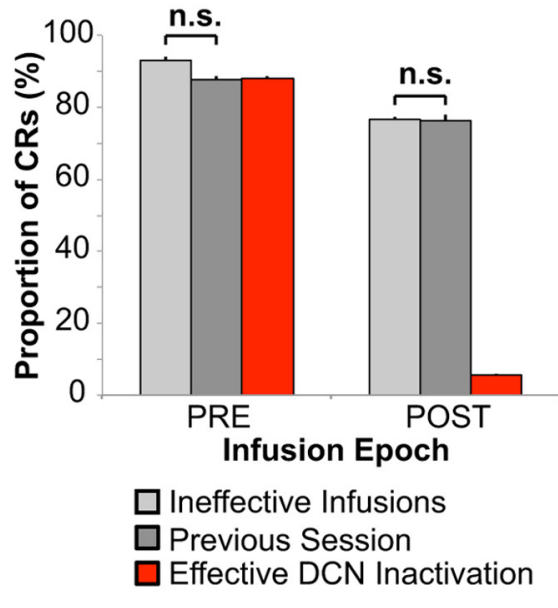

Figure 1. A, Top, Schematic of brain regions associated with the expression of learned responses in trace eyelid conditioning. The boxes show schematic representations of the neural activity that has been observed in that region during expression of conditioned responses. The temporal relationship between the TONE CS (gray bar) and the US (black arrowhead) is shown to the left and above/below each brain region, along with the timing of the conditioned eyelid closure driven by the DCN via the red nucleus (RN, right). Single neurons in the $\mathrm{mPFC}$ show three patterns of tone-evoked responses: phasic (upper spike train), persistent (middle), and those restricted to the trace interval (bottom). Heavier arrows show anatomical flow of inputs between the $C S$ and cerebellum. Lighter arrows point to brain regions previously shown to receive cerebellar output, which is reflected in the single-unit activity observed in those regions (e.g., bottom spike train in pons). Bottom, Schematic representation of the hypothesis tested in the current study: that persistent activity in the mPFC is upstream of the cerebellum whereas trace interval activity reflects downstream feedback from the output pathway of the cerebellum. To test this hypothesis, the DCN was inactivated with muscimol during trace eyelid conditioning and mPFC persistent and trace interval cells examined for changes in activity in the absence of cerebellar output and behavioral responses. $\boldsymbol{B}$, Top, Autofluorescent coronal sections with plots of the estimated infusion sites in the cerebellar deep nuclei for all rabbits in this study (cannula was targeted to the anterior interpositus nucleus). Each marker represents a single site, with one or two sites per rabbit (if an infusion site was or became ineffective a deeper infusion was attempted in 3 of the rabbits). Effective sites are shown in red and ineffective in black, with the amount of muscimol infused represented by the size of the marker (range, $2-5 \mu$ ). The open marker represents one site in which six successful infusions were done followed by a $1 \mu$ infusion of Alexa-conjugated dextran to estimate diffusion through the tissue. Bottom, Autofluorescent and dextran fluorescent images overlaid. Red fluorescence shows the spread of $1 \mu$ infusion of dextran. Scale bars, $1 \mathrm{~mm}$. C, Conditioned response likelihood during ineffective DCN infusions (light gray), noninfusion sessions (dark gray), and effective DCN infusions (red bars). CRs were abolished after effective DCN infusions (POST). The likelihood of CRs observed for ineffective infusion and noninfusion sessions were not different $\left(t_{(11.26)}=1.08, p=0.30\right)$, and so neural data from both session types were used as controls for comparison with successful DCN inactivation sessions. 


\section{PFC single-unit recording locations \\ - 0 Persistent \\ - O Phasic}

Effective Infusions
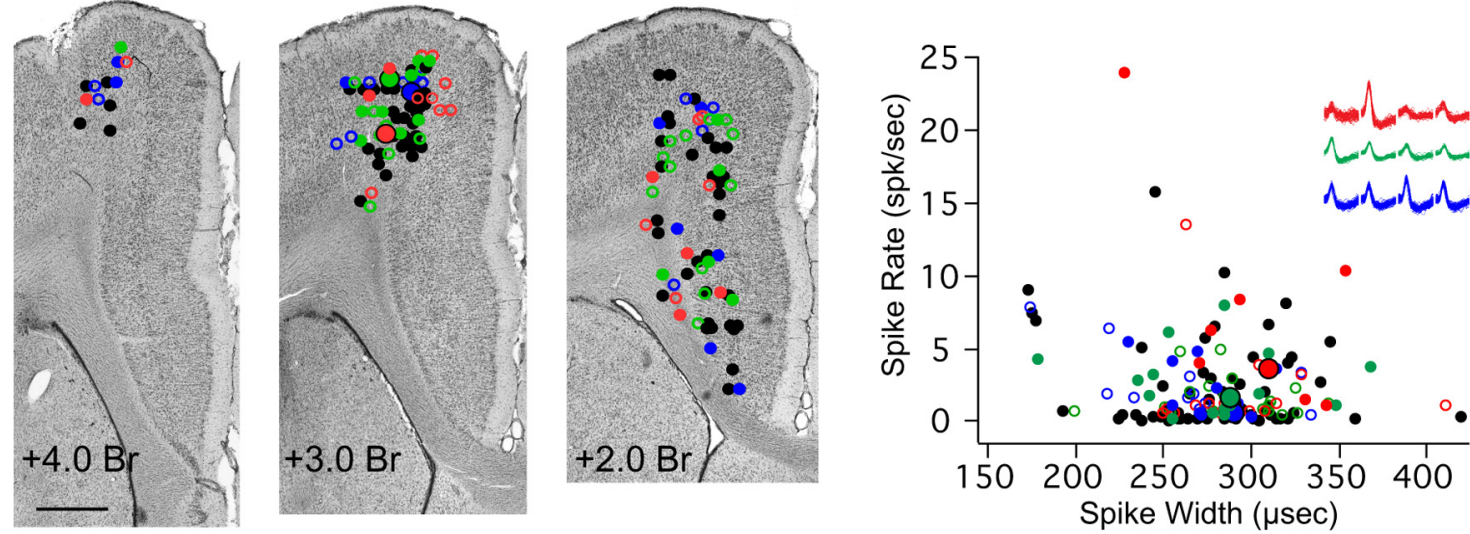

Previous Day (no infusion)
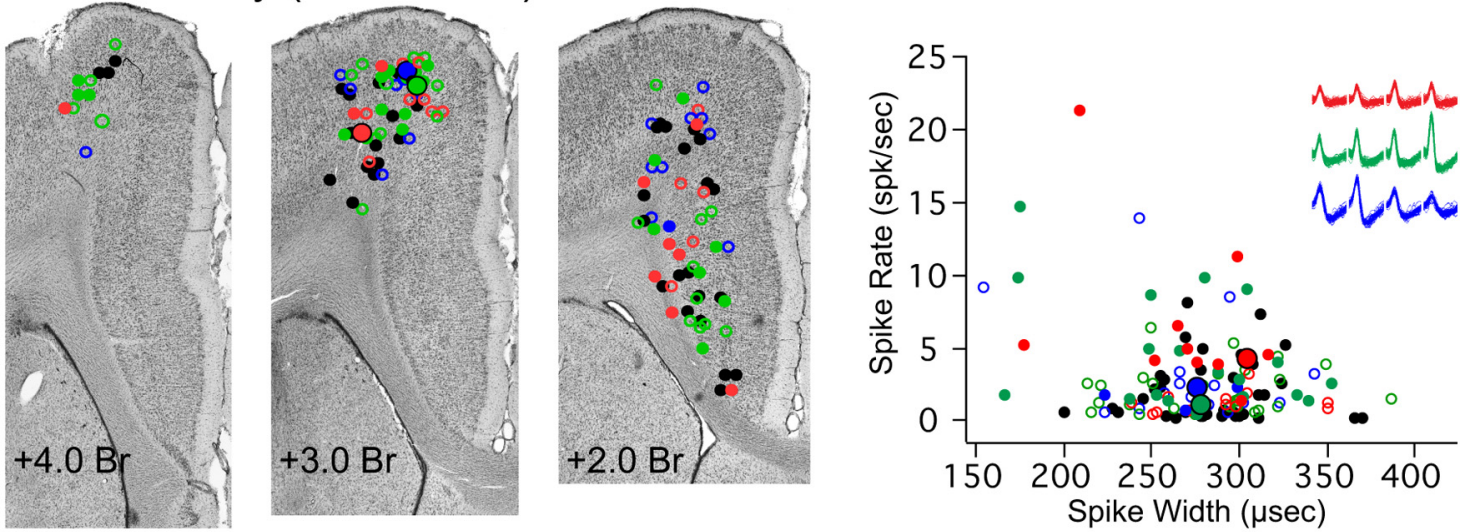

\section{Ineffective Infusions}
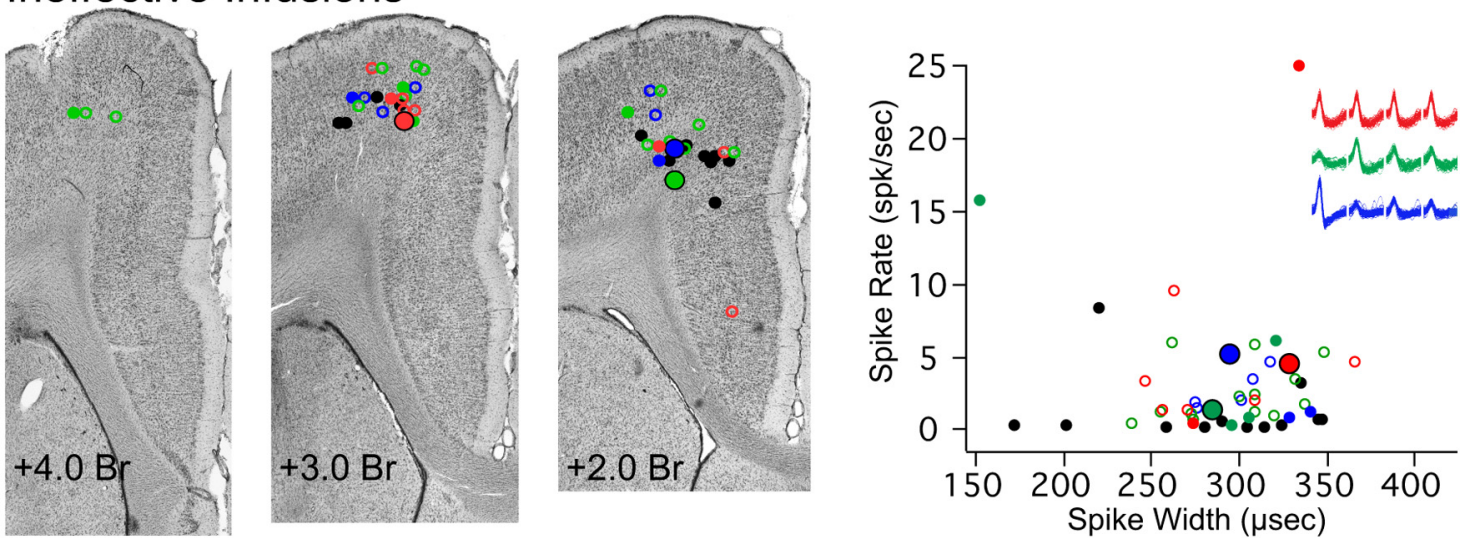

Figure 2. Estimated sites of single-unit activity for cells recorded during each condition (Effective, Previous Day, and Ineffective) and average waveform and activity parameters from each single unit used to distinguish between putative pyramidal cells and interneurons. Colored markers indicate single units that showed a given response type (red represents persistent; green represents phasic CS; blue represents trace interval; black represents US/post-trial/no response), and whether the cell increased (filled marker) or decreased (open marker) spike activity in response to conditioning stimuli. Left, Representative Niss-stained coronal sections at 3 locations along the rostrocaudal plane of the $\mathrm{mPFC}$, and plots of the estimated recording location of single-unit activity for each condition. All cells were recorded within the medial agranular or caudal anterior cingulate regions of the mPFC. Scale bar, $1 \mathrm{~mm}$. Right, Scatterplots of average spike width $\times$ average firing rate for each single unit, with representative examples of waveforms recorded from the four channels of a tetrode for 3 of the cell types analyzed, for each condition (color-coded as described above, with the single-unit for each example also highlighted with a larger marker with black outline in the scatterplots and coronal sections). Less than $5 \%$ of cells in each condition would be designated as putative interneurons based on spike width.

Briefly, isolated clusters of suprathreshold neural events with common waveform parameters were identified as single units, and the time stamps of those events (spikes) extracted and analyzed relative to the presentation of training stimuli and behavioral responses. Only single units with clustered points that showed little or no overlap $(<10 \%)$ with another cluster and with unisolated background activity were included in the analysis (Siegel et al., 2008, 2012). The spike width for each spike assigned to a cluster was calculated as the time between the peak and valley of the 
waveform. The average spike rate for each cluster of single-unit activity was calculated as the total number of spikes observed during a session divided by the length of that session (in seconds).

Histological procedures. At the conclusion of experiments, all rabbits were killed with an intravenous injection of Euthasol $(0.3 \mathrm{ml} / \mathrm{kg})$ and perfused intracardially with $0.9 \%$ saline followed by $4 \%$ paraformaldehyde. The brains were extracted and cryoprotected in a $30 \%$ sucrose solution before sectioning the $\mathrm{mPFC}$ and cerebellum on a freezing microtome $(50 \mu \mathrm{m}$ sections). Sections were mounted on Microfrost Plus slides (Fisher Scientific), dried overnight, then stained with cresyl violet to visualize tetrode or cannula tracks and surrounding anatomical structures. Approximate recording locations of single-unit activity were determined and plotted on representative images as previously described (Siegel et al., 2012). The sections of cerebellum from the rabbit that received the fluorescent dextran infusion were cleared with xylenes and coverslipped with DPX mounting medium. Fluorescent images were acquired with a Zeiss Imager Z2 microscope. Images of background autofluorescence were taken to visualize anatomical structure (Zeiss filter set 38; excitation BP 470/40, dichroic FT 495, emission BP 525/ 50 ), whereas conjugated dextran was visualized using the appropriate Alexa-594 filter set (Zeiss set 71; excitation BP 594/24, dichroic FT 615, emission BP 675/100).

Analysis. Three analyses were used to assess the effects of DCN inactivation on isolated single-unit responses to trace eyelid conditioning: a categorical analysis to determine whether cells qualified for the same response category before and after infusions, a spike response analysis to determine whether there were changes in spike rate as a result of DCN inactivation, and a final analysis to examine the time course of changes in spike responses within and across trials.

Categorical analysis. For each isolated single unit, the spikes observed during each trial of a session were assigned to $100 \mathrm{~ms}$ time bins, beginning $1 \mathrm{~s}$ before CS onset and extending $3 \mathrm{~s}$ after US onset (Siegel et al., 2012). The average number of spikes observed for the 10 bins before CS onset was used as the baseline activity for that trial. The statistical reliability of changes in spike activity for each time bin across the trials in a session was determined by comparing the number of spikes observed in that bin with the average baseline activity for each trial. For each time bin ( 5 bins during the CS, 5 bins during the trace interval, and 30 US and post-trial bins), a significant change in spike activity was determined with a paired $t$ test between the number of spikes observed for that bin and the baseline (with Bonferonni correction for the number of time bin comparisons, $\alpha=$ 0.05/40 time bins, $p<0.00125)$.

Single units were then categorized according to the pattern of significant changes in activity during trace conditioning trials (Siegel et al., 2012). "Persistent" responses were defined as a significant increase (or decrease) in spike activity that began before the end of the CS and persisted at least 2 bins into the trace interval (e.g., see Fig. $3 A, c 9.1$, and Fig. previous day.

\section{A Responses of mPFC cells to DCN Inactivation}

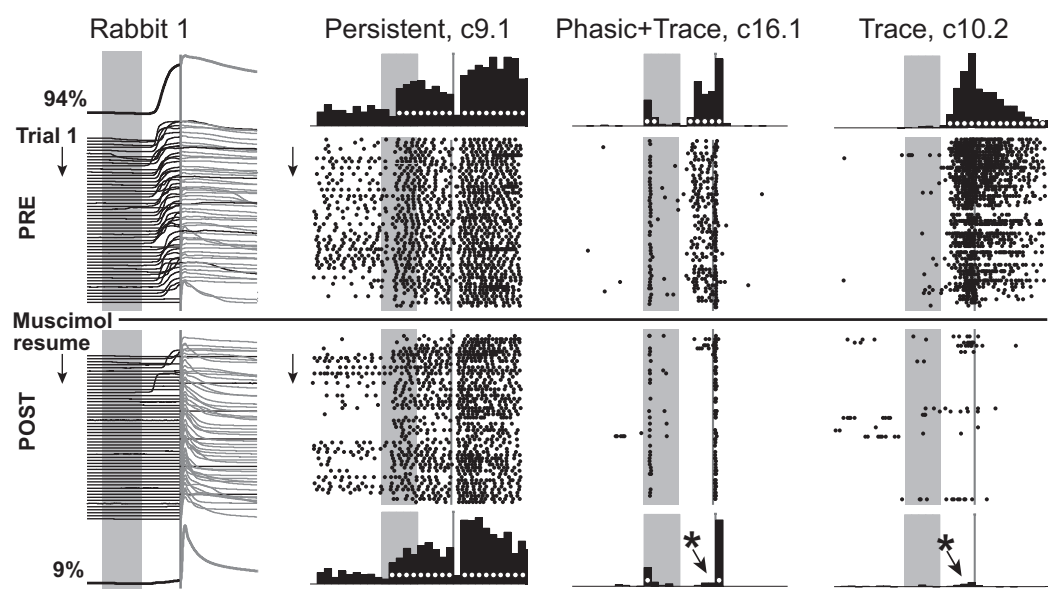

B Responses of mPFC cells during previous session Control

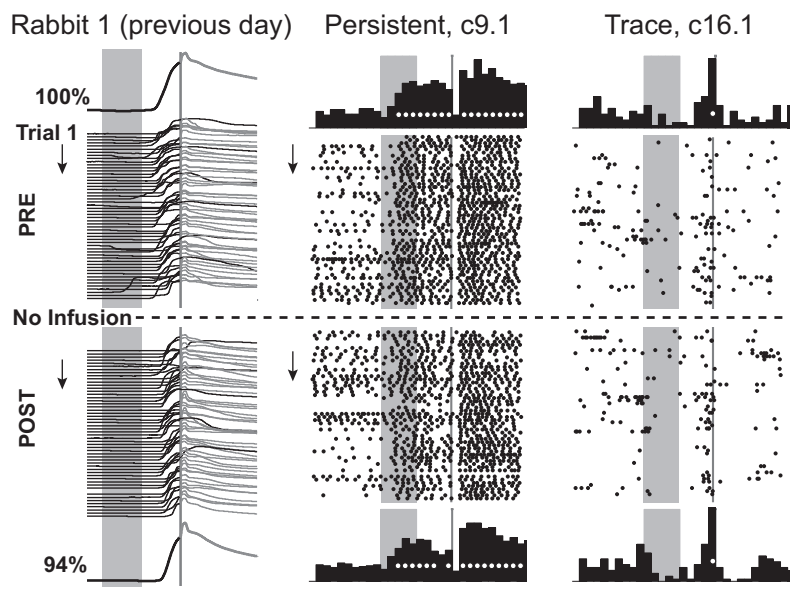

Figure 3. Representative examples of behavioral and simultaneously recorded single-unit responses before (PRE) and after (POST) DCN inactivation $(\boldsymbol{A})$, and examples from the control session recorded on the previous day from the same animal $(\boldsymbol{B}) . \boldsymbol{A}$, Eyelid responses (waterfall plot) for individual trials before (PRE) and after (POST) DCN inactivation with muscimol; upward deflection indicates eyelid closure, gray rectangles represent onset and duration of the $C S(500 \mathrm{~ms})$; gray line $(50 \mathrm{~ms})$ indicates timing of the US. The average preinfusion eyelid response is shown above the individual trial examples, and the average postinfusion eyelid response is shown below. The percentage conditioned responses before and after infusion are also indicated. There are anticipatory eyelid closures during the trace interval before US presentation during the preinfusion epoch, with few observed during the postinfusion epoch. The rabbit in this and the following figures still shows full amplitude reflexive responses during DCN inactivation in the absence of CRs. Raster plots represent the spike activity of three isolated single units (type of categorical response and cluster identification given above, e.g., the first example was recorded from tetrode 9 as cluster number 1). Stimulus markers are the same as the behavioral data. Each row of a raster plot represents one trial and includes a $1 \mathrm{~s}$ baseline before and after the trial, with dots indicating the occurrence of a single spike. Histograms show cumulative number of spikes for $100 \mathrm{~ms}$ bins for preinfusion trials (top row) and for postinfusion trials (bottom row). White markers in the histograms indicate time bins with significant increases in activity relative to baseline. * Significant changes in activity for postinfusion trials. This infusion abolished conditioned responses (left) and trace interval activity (c16.1 and c10.2) but did not change persistent tone-evoked response patterns (c9.1). c16.1 displayed a significant phasic tone response that was still observed after DCN infusion while the trace interval response was abolished along with the learned behavior. B, Changes were not observed for persistent (left raster/histograms) or trace interval (right) single-unit responses from cells recorded on the same tetrodes during a noninfusion control session taken the

4), based on the timing parameters of inputs previously shown to engage cerebellar learning in rabbits (Kalmbach et al., 2009). "Trace interval" responses began after CS offset and before US onset (e.g., see Fig. 3, c16.1 and c10.2, and Fig. 5). A third response type was "phasic" responses to the $\mathrm{CS}$ that began during the $\mathrm{CS}$ but failed to meet persistent criteria (e.g., see Fig. $3 A$, c16.1, and Fig. 5A, c21.1). Initial categorization was based on the response profile observed before infusions, or for the first half of the session for noninfusion controls. Single units were then recategorized based on the response profile observed after the expression of CRs was pharmacologically blocked (or during the second half of the 


\section{A Responses of Tone-evoked Persistent activity to DCN Inactivation}
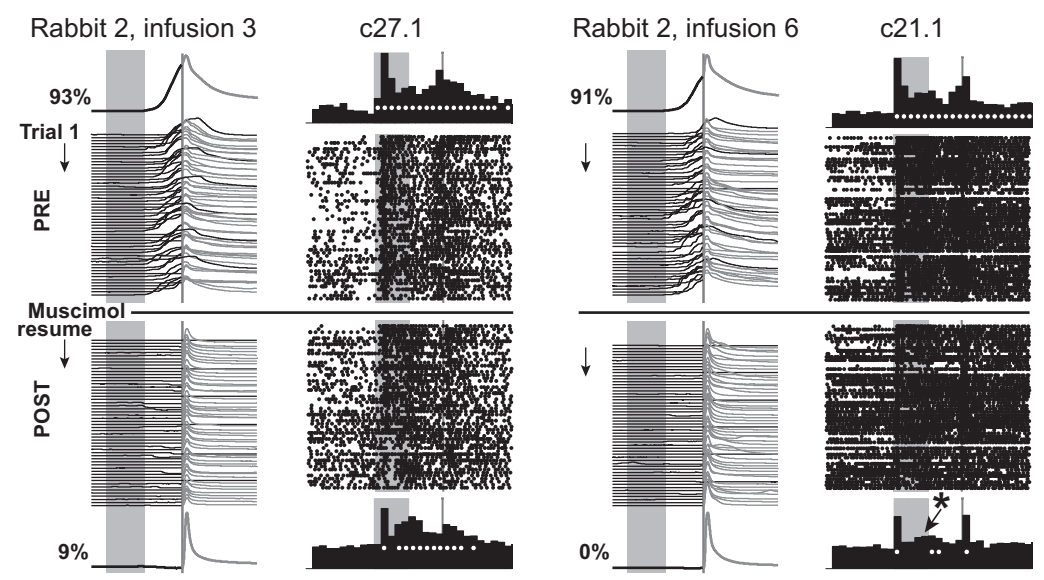

B Responses of Tone-evoked Persistent activity during Control
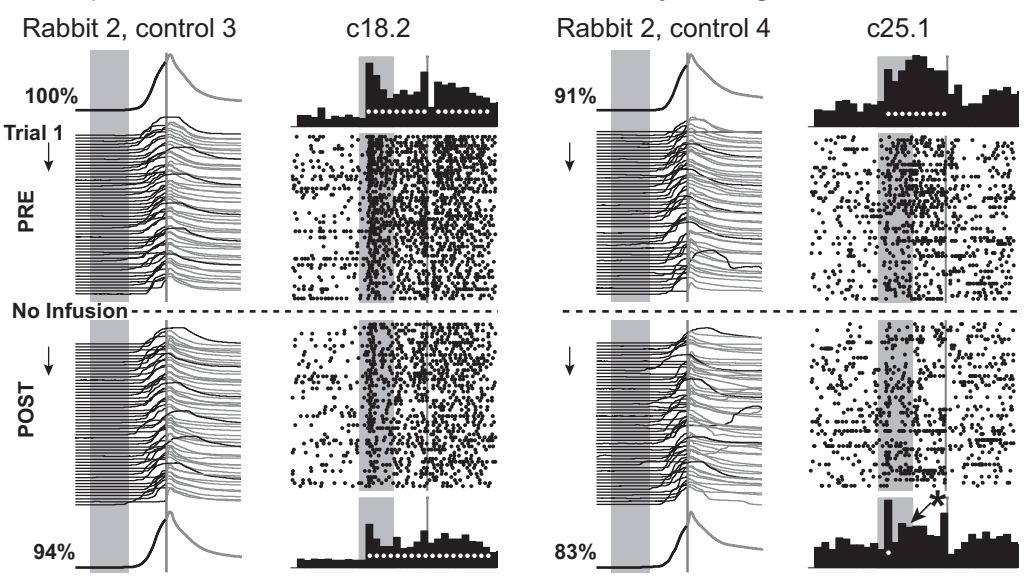

Figure 4. Additional examples of persistent mPFC cell activity during DCN inactivation and during control sessions, with figure layout as described for Figure 2. Examples of a single-unit response that did not change (left) and one that did change (right) are given for both inactivation $(\boldsymbol{A})$ and control sessions $(\boldsymbol{B})$. A similar proportion of mPFC cells showed a change in activity pattern during both inactivation and control sessions. For both infusion and control sessions, changes in persistent responses were often one of consistency during the last half of the session that did not meet statistical criteria relative to baseline, and did not reflect a complete absence of the activity pattern.

session for controls). Cells that failed to qualify for the same category during DCN inactivation were scored as showing a change in response pattern.

Analysis of changes in spike activity during the trace interval. For each single-unit categorized as showing persistent or trace interval responses, differences scores were calculated by subtracting the average number of spikes during the $500 \mathrm{~ms}$ trace interval across preinfusion trials from that observed during the postinfusion trials of a given session (or for the first and second halves of noninfusion control sessions). Phasic tone cells were also analyzed by calculating the difference between the average number of spikes observed during the $500 \mathrm{~ms}$ CS epoch between preinfusion and postinfusion trials. The pre-post difference scores were compared between control and infusion sessions for each response type (two-tailed $t$ tests with Bonferroni correction across response types). To further test whether decreased spike responses during the trace interval were abolished to baseline levels, difference scores for persistent and trace interval cells were calculated by subtracting the average number of spikes observed during the trace interval from that observed during a $500 \mathrm{~ms}$ baseline. (or between the CS period and baseline for phasic tone cells). We compared the difference scores across the three cell types before and after infusions (two-tailed paired $t$ test, $\alpha=0.05$ with Bonferroni correction for family wise comparisons).

Analysis of binned and averaged raster plots. The activity changes of $\mathrm{mPFC}$ persistent and trace interval cells were analyzed within and across trials by transforming the raster plots of each single-unit to a matrix. For each cell, spikes were assigned to $100 \mathrm{~ms}$ bins across each trial ( $x$-axis; 10 pretrial bins, 5 CS bins, 5 trace interval bins, 10 post-trial bins) while conserving individual trials on the $y$-axis. The resulting $30 \times 108$ bin matrix of each cell (number of trial bins $\times$ number of trials) was normalized by subtracting the average number of spikes per bin observed during the pre-CS baseline from the entire matrix. The matrices of persistent and trace interval cells were averaged together according to response type and experimental condition (control or DCN inactivation), and smoothed by a single pass with a $3 \times 3$ median filter. Analysis that tested for changes in activity across blocks of trials within a session ( 9 trials/block) was used to examine the time course of changes in spike activity during the trace interval after DCN inactivation (i.e., along the $y$-axis; unpaired two-tailed $t$ tests, $\alpha=0.05$ with Bonferonni correction within cell type). Analysis across the trial time $(x$-axis) examined changes in activity in response to presentation of trace conditioning stimuli (Kolmogorov-Smirnov test, $\alpha=0.05$ with Bonferonni correction within cell type).

\section{Results}

We used cerebellar inactivation to block the motor output that drives CRs to investigate whether the persistent and/or trace interval responses observed in the mPFC may reflect a kind of feedback from the cerebellar output pathway and which pattern(s) do not, and so would remain viable candidate input patterns from the mPFC to the cerebellum (Fig. $1 \mathrm{~A}$, bottom). We also analyzed cells that showed "phasic" CS-evoked responses as a within manipulation control, given that such a response pattern does not overlap with the US and therefore would be unable to engage cerebellar learning. Any changes in phasic spike responses as a result of cerebellar inactivation would reflect a more global effect on mPFC cells beyond the specific response patterns hypothesized to directly support the task.

\section{Effects of muscimol infusion in the cerebellum on trace conditioned responses}

Infusions of muscimol into the cerebellum had a bimodal effect on CRs. The expression of CRs was either abolished (mean CR\% after infusion $=05.5 \pm 0.5$, range $0-21 \%, 15$ sessions from 5 rabbits; examples given as waterfall plots in Figs. $3 A, 4 A$, and $5 A$; for specific criteria, see Materials and Methods), or little to no effect was observed (mean $\mathrm{CR} \%$ after ineffective infusion = $76.5 \pm 0.8$, range $69-85 \%, 6$ sessions from 4 rabbits). Ineffective infusions may have been the result of misplaced or obstructed cannula. Figure $1 B$ shows the locations of each infusion site and the estimated diffusion of drug (based on the maximum volume infused at that site). Infusion sites that were ventral or posterior to the anterior interpositus were either ineffective or required greater volumes of drug to be infused to abolish learned responses. However, even at effective sites that were well targeted to the anterior interpositus, it is likely that the drug also diffused to 
neighboring nuclei. Therefore, we will refer to effective infusions more generally as anterior DCN inactivations. For the present study, the overriding goal was to compare mPFC single-unit responses between abolished versus intact expression of CRs. It should be noted that, although no partial effects of DCN infusions were observed, two rabbits (4 sessions) showed a delay in the onset of CR abolition by 10-30 trials (e.g., see Fig. 5A), presumably reflecting the time required for the muscimol to diffuse to the effective region. For these sessions, analysis of changes in mPFC spike responses during trace conditioning trials was adjusted according to the delayed onset (for behavioral criteria to define effective DCN inactivation, see Materials and Methods). Because the behavior between ineffective infusion and noninfusion sessions was not different $\left(t_{(11.26)}=1.08, p=0.30\right.$; Fig. $\left.1 C\right)$, neural data from both session types were pooled as control data for comparison with effective DCN inactivation sessions.

\section{Single-unit activity recorded during trace eyelid conditioning}

A total of 323 single units were recorded from the mPFC of 6 rabbits over 35 trace conditioning sessions (averaging 54 cells/ rabbit and 9 cells/session). Effective DCN inactivation was observed during 15 of the 21 cerebellar infusion sessions $(n=147$ cells from 5 rabbits, each contributing $44,39,32,30$, and 2 cells, respectively). Tetrodes with single-unit activity were moved a minimum of $160 \mu \mathrm{m}$ between infusion sessions, and so cells recorded over more than one session from the same rabbit represent unique samples of $\mathrm{mPFC}$ neurons relative to other infusion sessions recorded from the same animal. Sessions from ineffective infusions served as infusion control sessions ( $n=47$ cells during 6 sessions from 4 rabbits). Sessions recorded one day before effective inactivation sessions served as noninfusion controls that likely included activity from many of the same single units as were recorded during effective infusion sessions because the tetrodes were not adjusted between these 2 days $(n=129$ cells during 14 sessions from 5 rabbits, each contributing 50, 21, 36, 20 , and 2 cells, respectively; the session before one effective inactivation was an ineffective infusion). As described above, data from both types of controls were pooled for comparison with data from effective DCN inactivation sessions.

The estimated recording sites of all cells in all conditions were located within the medial agranular cortex and caudal anterior cingulate regions of the mPFC (Fig. 2, color-coded according to response type), primarily from layers 5/6. Sixty-four percent of single units showed significantly increased or decreased spike activity in response to the CS during trace conditioning. As previously reported, some cells showed changes that persisted beyond CS offset into the trace interval ("persistent," 22 increasing and 32 decreasing, 17\% of all cells recorded), whereas others
A Responses of Trace Interval activity to DCN Inactivation

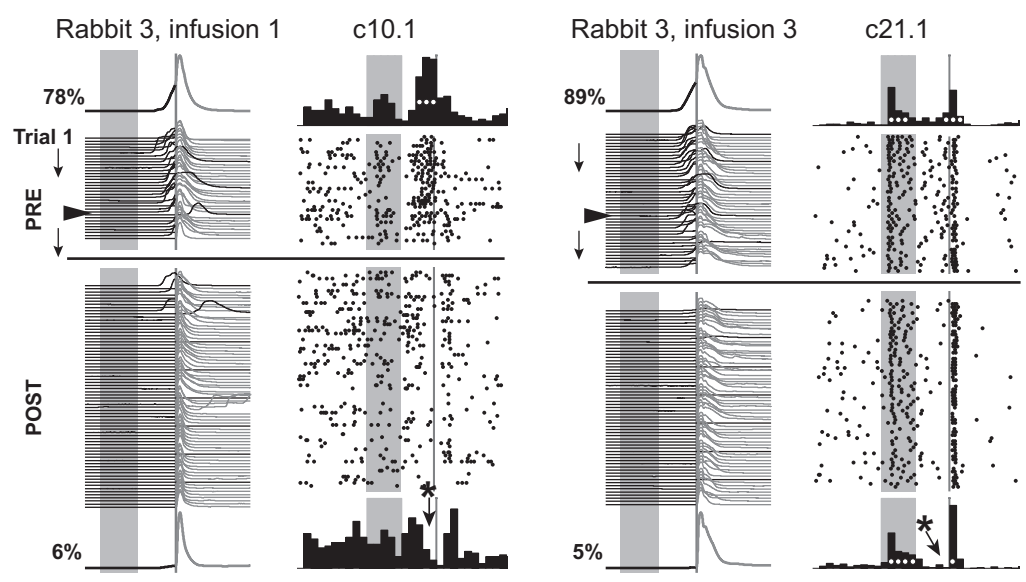

B Responses of Trace Interval activity during Control
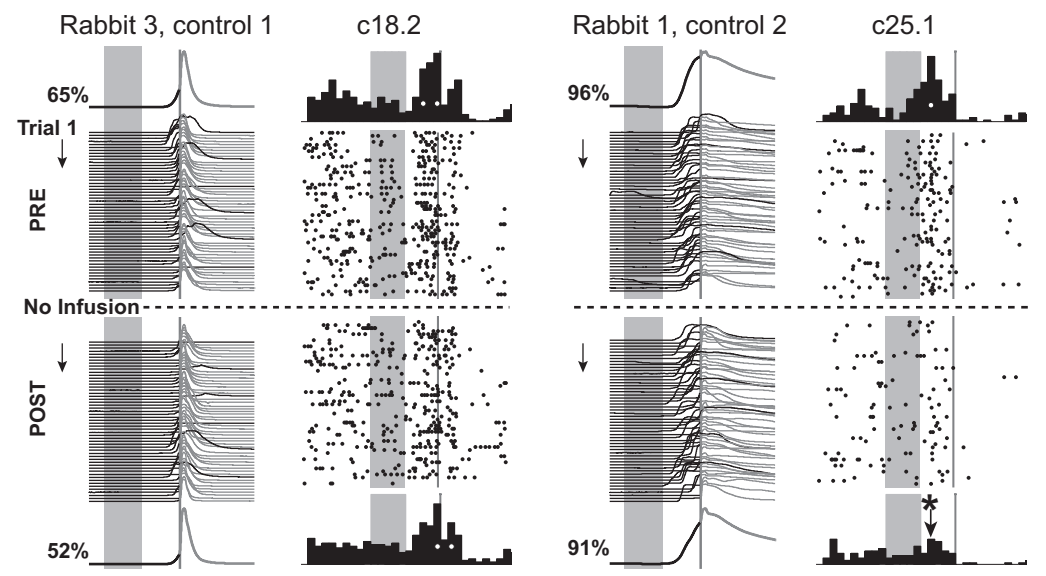

Figure 5. Additional examples of trace interval activity during DCN inactivation and during control sessions, with figure layout proportion showed significant changes during control sessions (e.g., $\boldsymbol{B}$ ). In most cases, trace interval activity that changed during control sessions showed significant increases in activity early in the trace interval, before the onset of behavioral responses, which was not typical for that response type $(\boldsymbol{B}, \mathbf{c} 25.1)$. $\boldsymbol{A}$, The data are examples in which analysis has been corrected for the delayed effects of DCN inactivation. Arrowheads in waterfall plots indicate the actual time of muscimol infusion.

showed phasic CS responses ("phasic," 39 increasing and 61 decreasing, $31 \%$ of all cells) or responses with onsets during the trace interval ("trace," 33 increasing and 77 decreasing, $34 \%$ of all cells) (Siegel et al., 2012). Previous work suggests that the spike width of extracellularly recorded action potentials in conjunction with average spike rates can be used to differentiate between prefrontal pyramidal cells and interneurons in vivo (Tierney et al., 2004; Tseng et al., 2006; Dilgen et al., 2013). Scatterplots of the average spike width and firing rate for each single unit from each session suggested that only a small subset of recordings were from putative interneurons ( $\sim 5 \%$ from each condition; Fig. 2$)$. Importantly, no response type (persistent, phasic, or trace) was overrepresented by putative interneurons. No significant difference in spike width was observed among response types showing increased activity during effective infusions $(n=8,15$, and 10 cells, respectively, $F_{(2,30)}=1.21, p=0.31$ ) or among response types recorded during noninfusion control sessions $(n=14,25$, and 7 cells, respectively, $\left.F_{(2,32)}=0.01, p=0.99\right)$. Furthermore, the spike widths and average firing rates of persistent, phasic, or trace cells were not significantly different between effective infusion and noninfusion controls (persistent: $n=8$ and 14 cells, respectively, width: $t_{(15.32)}=1.60, p=0.13$, rate: $t_{(12.25)}=0.30$, 
A Consistency of mPFC Activity Patterns during Controls

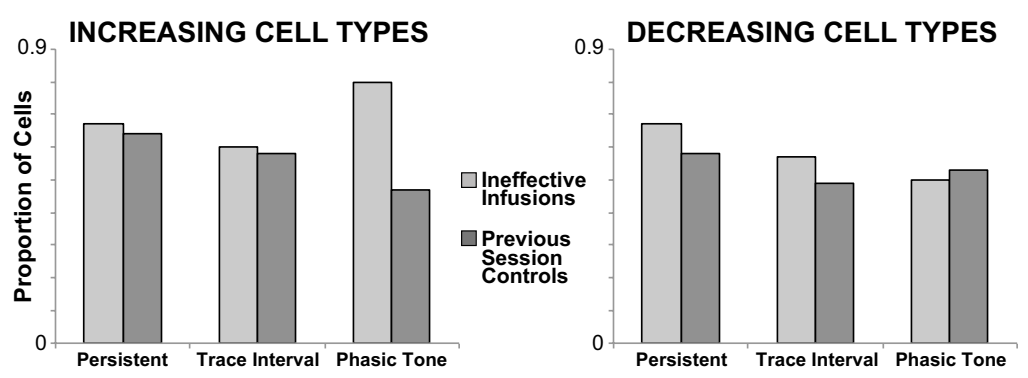

B Consistency of mPFC Activity Patterns during DCN Inactivation

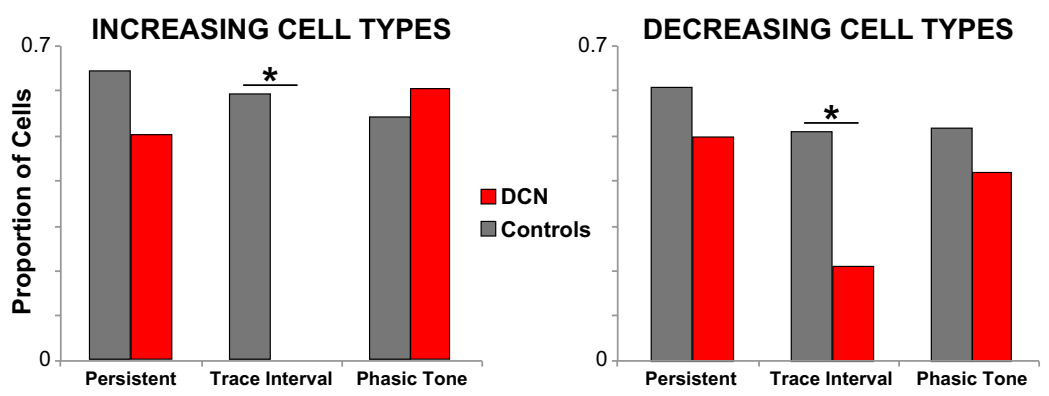

Figure 6. Proportions of $\mathrm{mPFC}$ cell types that maintained the same response pattern for two control conditions $(\boldsymbol{A})$, and between DCN inactivation and pooled control sessions $(\boldsymbol{B})$. $\boldsymbol{A}$, Cells were categorized as persistent, trace interval, or phasic based on response patterns during the first half of control sessions, and then categorized again during the second half of control sessions. Similar proportions of mPFC single-unit response types continued to meet the same categorical criteria for both control session types (light gray represents ineffective DCN infusions; dark gray represents noninfusion sessions from the previous day; persistent increase: ineffective infusion vs previous day, $n=3,11, \chi^{2}=0.01, p=0.56$; trace increase: $n=5,12, \chi^{2}=0.004, p=0.63$; phasic increase: $n=5,19, \chi^{2}=1.70, p=0.42$; persistent decrease: $n=6,12, \chi^{2}=0.12, p=0.86$; trace decrease: $n=14,39$, $\chi^{2}=0.29, p=0.59$; phasic decrease: $n=14,28, \chi^{2}=0.05, p=0.83$ ). Therefore, mPFC cells recorded during both control types were pooled for control comparisons with cells recorded during DCN inactivation. $B$, Compared with controls, DCN inactivation significantly affected the response pattern of trace interval cells but did not significantly affect the activity patterns of persistent or phasic tone cells (DCN vs controls, persistent increase: $n=8,14, \chi^{2}=0.43, p=0.51$; trace increase: $n=16,17, \chi^{2}=13.50$, $p=0.0002$; phasic increase: $n=15,24, \chi^{2}=0.13, p=0.72$; persistent decrease: $n=14,18, \chi^{2}=0.40, p=0.53$; trace decrease: $n=24,53, \chi^{2}=6.17, p=0.01$; persistent decrease: $\left.n=19,42, \chi^{2}=0.55, p=0.46\right)$. * Bonferroni-corrected, $p<0.017$.

$p=0.77$; phasic: $n=15$ and 25 cells, width: $t_{(32.07)}=0.42, p=$ 0.67 , rate: $t_{(31.42)}=1.56, p=0.13$; trace: $n=10$ and 7 cells, width: $t_{(4.46)}=0.37, p=0.73$, rate: $\left.t_{(12)}=0.87, p=0.40\right)$. The results suggest that the large majority of single-unit recordings during DCN inactivation and control sessions were from pyramidal neurons, and that the different response types did not have different spike widths or average firing rates.

\section{Effects of DCN inactivation on categories of mPFC spike responses}

As an initial analysis, we evaluated whether each cell categorized as persistent, trace interval, or phasic tone continued to meet the same category criteria after DCN inactivation. Analysis was primarily focused on cells that showed increases in activity in response to conditioning stimuli, given that increased responses that overlap in time with the US are hypothesized to drive CR expression in downstream brain areas. It was typical during control sessions for some persistently increasing cells to alter their response pattern such that they failed to meet the same criteria during the second half of the session, whereas most maintained a significant persistent increase in spike response ( $n=9$ of 14 cells from 12 sessions/5 rabbits; e.g., Figs. 3B, c9.1, and $4 B$, c18.2). During DCN inactivation, a similar proportion of persistent cells maintained persistently increased spike responses as that observed during control sessions $(n=4$ of 8 cells from 6 sessions/ 4 rabbits, see Fig. $6 B ; \chi^{2}=0.43, p=0.51$; e.g., Figs. $3 A$, c9.1, and $4 A$, c27.1). Of the cells that failed to meet criteria as persistent during $\mathrm{DCN}$ inactivation, most displayed a similar overall pattern that was simply less robust over the second half of the session during the DCN infusion (e.g., Fig. 4A, c21.1, $B$, c25.1). Cells that displayed a persistent decrease in activity were similarly unaffected by DCN inactivation relative to controls (DCN: $n=7$ of 14 cells from 6 sessions/ 3 rabbits, control: $n=11$ of 18 cells from 11 sessions $/ 5$ rabbits, $\chi^{2}=0.40, p=0.53$; see Fig. $6 B$ ). Likewise, cells that displayed phasic increases and decreases were also unaffected by the abolition of CRs (increasing: $n=9$ of 15 cells from 9 sessions/4 rabbits vs 13 of 24 cells from 14 sessions/ 6 rabbits, $\chi^{2}=0.13, p=0.72$; decreasing: $n=8$ of 19 cells from 10 sessions/5 rabbits vs 22 of 42 cells from 17 sessions/6 rabbits, $\chi^{2}=0.55, p=0.46$; see Fig. $6 B$ ). The apparent failure of DCN inactivation to affect the response pattern of persistent and phasic tone mPFC cells suggests that these responses were not significantly affected by the abolition of CRs.

In contrast, every mPFC neuron characterized as a trace interval increasing cell failed to meet the same category criteria when CRs were abolished by DCN inactivation $(n=0$ of 16 cells from 10 sessions $/ 5$ rabbits that maintained trace interval activity; Figs. $3 A$ and $5 A$ ). In control sessions, a proportion of trace interval cells also failed to remain in the same category ( $n=7$ of 17 cells from 9 sessions $/ 5$ rabbits), but the proportion was significantly higher than DCN inactivation sessions $\left(\chi^{2}=13.50, p<0.001\right.$; Fig. $\left.6 B\right)$. In many cases, trace interval increasing cells also showed phasic tone and/or US associated responses that were unaffected by DCN inactivation, with the trace interval activity selectively abolished along with the behavioral responses (e.g., Figs. $3 A$, c16.1, and $5 A$, c21.1). Similarly, for decreasing trace interval cells, a higher proportion of neurons changed category during DCN inactivation relative to controls (only 5 of 24 cells from 11 sessions/4 rabbits maintained trace interval responses vs 27 of 53 cells from 18 sessions $/ 6$ rabbits for controls, $\chi^{2}=6.17, p=0.013$; Fig. $6 B$ ). The robust effect of DCN inactivation on trace cell activity suggests that the source of input driving this $\mathrm{mPFC}$ response pattern is somewhere downstream from cerebellar output.

\section{Effects of DCN inactivation on the spike activity of mPFC persistent and trace responses}

As a second analysis, we tested whether mPFC response types showed changes in spike activity as a result of DCN inactivation. We focused this analysis on changes in the number of spikes observed during the trace interval after DCN inactivation for both persistent and trace interval cells, given that this is the time frame during which input to the cerebellum is necessary to support trace eyelid conditioning. For each cell, a change in spike activity was taken as the difference in the average number of spikes per trial observed during the trace interval in the preinfusion trials versus the same measure in the postinfusion trials (or 
first half trials vs second half trials for control sessions). For phasic tone cells, the difference in the average spike activity per trial observed during the CS period was used.

The pre-post difference scores observed for all three cell types during control sessions and DCN inactivation sessions are given in Figure 7. The difference scores during control sessions revealed that all three cell types typically show a decrease in spike activity between the first and second half of trace conditioning sessions (persistent: $n=14, t_{(13)}=$ 2.48, $p=0.028$; trace: $n=15, t_{(14)}=3.26$, $p<0.005$; phasic tone: $n=25, t_{(24)}=3.26$, $p<0.003$; Figure 7, gray bars). Given that all three $\mathrm{mPFC}$ response types show a typical decline in spike responses during the session, to evaluate the effect of DCN inactivation the decrease observed during infusions was compared with the typical decrease observed during control sessions. During DCN inactivation, persistent and phasic tone cells showed decreases in spike activity that were comparable with those observed during control sessions (persistent: $n=8$ and 14 cells for DCN and controls, respectively, $t_{(7,13)}=0.34, p=0.74$; phasic tone: $n=15$ and 25 cells, $t_{(14,24)}=0.62, p=0.54$; Figure $7 A, C$, left graphs, compare gray bars and red bars), even though rabbits showed a significant decrease in the expression of CRs during these sessions (persistent: $n=6$ and 12 sessions for DCN and controls, respectively, $t_{(5,11)}=15.77, p<0.001$; phasic: $n=$ 9 and 14 sessions, $t_{(8,13)}=14.07, p<0.001$; Figure $7 A, C$, right bar graphs). In contrast to persistent cells, the infusion-related decline in trace cell responses was significantly greater than that observed during control sessions $(n=16$ and 16 cells for DCN and controls, respectively, $t_{(15,15)}=2.51, p=$ 0.02 ; Fig. $7 B$, compare gray bars with red bars), corresponding to the decrease in CR performance during these sessions $(n=10$ and 9 sessions, $\left.t_{(9,8)}=13.58, p<0.001\right)$.

The results suggest that the spike activity of trace cells is significantly decreased during DCN inactivation, whereas the spike activity of persistent and phasic tone cells was not different from control sessions. To further test whether the spike activity of trace interval cells was abolished to baseline, we compared the average number of spikes observed during the trace interval during DCN inactivation with the average number of spikes observed during the pretrial baseline period.

During control infusions, the spike activity of all cell types, including trace cells, was significantly greater than baseline (persistent: $t_{(13)}=3.29, p=0.005$; trace: $t_{(15)}=3.40, p=0.004$; phasic tone: $t_{(24)}=4.83, p<0.001 ; n=14,16$, and 25 cells, respectively;

\section{Change in mPFC activity Change in Behavior}

\section{A Persistent Cells}
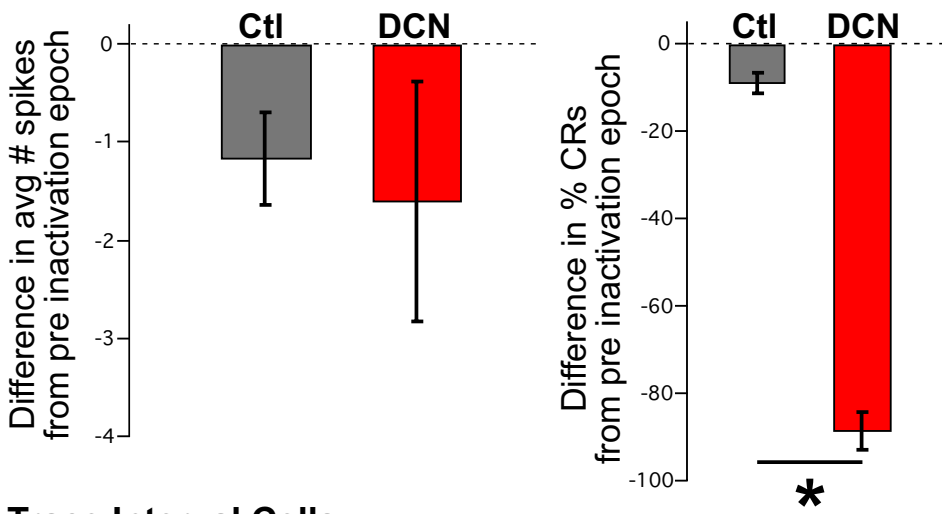

B Trace Interval Cells

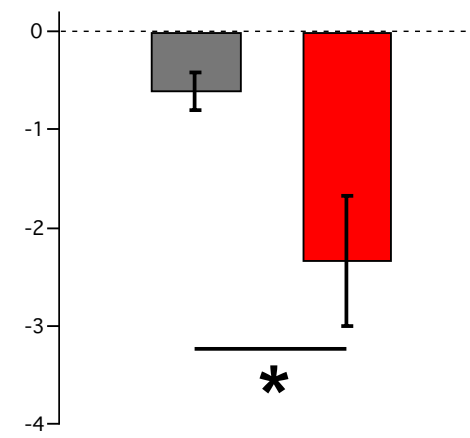

C Phasic Tone Cells
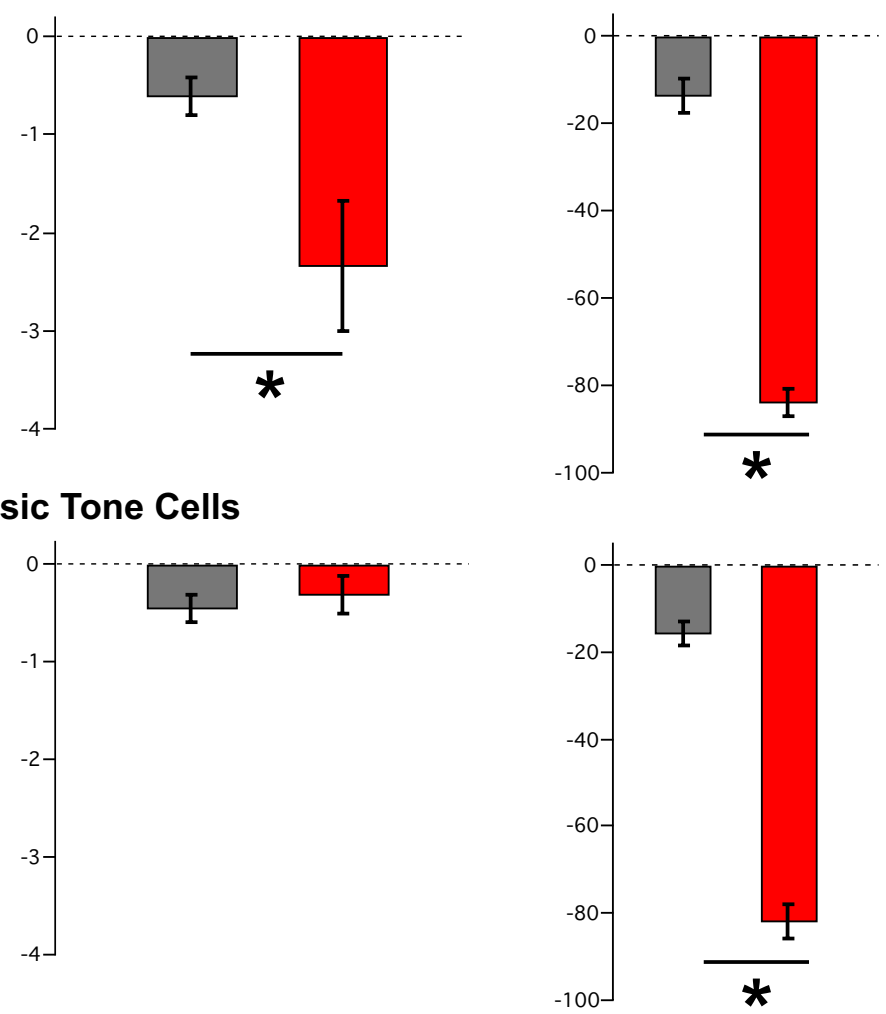

Figure 7. Average difference scores of the number of spikes observed during the trace interval before and after DCN inactivation for $\mathrm{mPFC}$ persistent $(\boldsymbol{A})$, trace $(\boldsymbol{B})$, and phasic tone $(\boldsymbol{C})$ cell response types, and difference scores for the expression of CRs within the sessions in which those cells were recorded. $A$, Difference scores derived from the average number of spikes observed during the stimulus-free trace interval between pre-DCN and post-DCN infusion epochs (red bars) were not significantly different from controls (gray bars) for persistent cells (left: $n=8$ and 14 cells, $t=0.34, p=0.74$ ), even though a significant difference in CRs was observed for sessions in which those cells were recorded (right: $n=6$ and 12 sessions, $t=15.77, p<0.001$ ). $\boldsymbol{B}$, In contrast, trace interval cells showed a significant decrease in the post-pre difference in the average number of spikes observed between DCN infusion and control sessions (left: $n=16$ and 16 cells, $t=2.51, p=0.02$ ), as was also observed for the change in behavioral responses from those sessions (right: $n=10$ and 9 sessions, $t=13.58, p<0.001$ ). C, As a within manipulation control, phasic tone cells were analyzed for differences in post-pre average spike responses during the tone $C S$ and showed no significant difference between control and DCN inactivation sessions (left: $n=15$ and 25 cells, $t=0.62, p=0.54$ ) even though the behavioral responses were different during the corresponding sessions (right: $n=9$ and 14 sessions, $t=14.07, p<0.001$ ). *Bonferroni-corrected, $p<0.017$.
Figure 8, left bar graph). During DCN inactivation, when CR expression was pharmacologically blocked, the spike responses of trace cells were not different from pretrial baseline activity $(n=$ 16 cells, $t_{(15)}=2.19, p=0.024$; familywise $\alpha$ for all six compari- 


\section{Increase from Baseline after DCN inactivation}
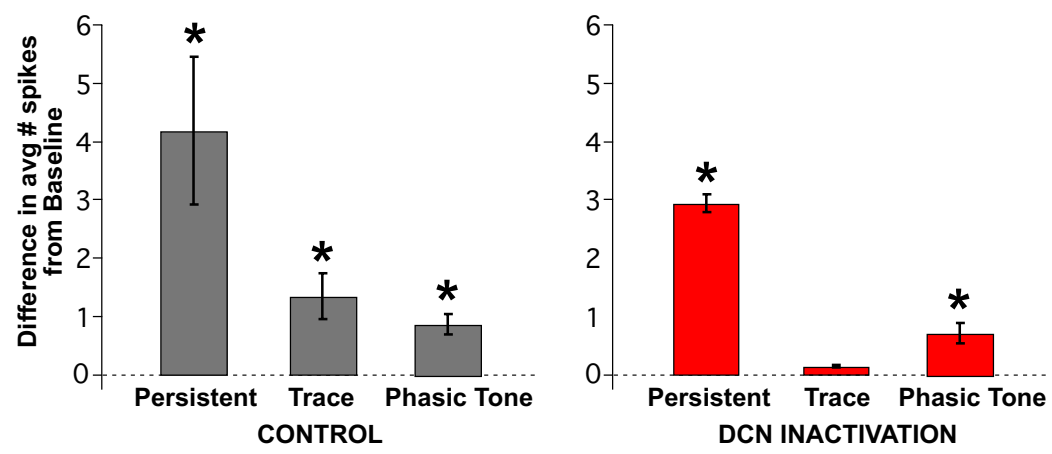

Figure 8. All three $\mathrm{mPFC}$ response types maintained significant increases in activity relative to baseline during the second half of control sessions (left bar graph: persistent, $n=14$ cells, $t=3.29, p=0.005$; trace, $n=16, t=3.40, p=0.004$; tone, $n=25$, $t=4.83, p<0.001$ ), whereas only persistent and phasic tone response types maintained significant increases in activity during DCN inactivation (right bar graph: persistent, $n=8, t=4.36, p=0.002$; trace, $n=16, t=2.19, p=0.024$; tone, $n=15, t=$ $4.15, p<0.001$ ). The activity of trace interval cells was not different from baseline activity during DCN inactivation, indicating that this pattern of activity was abolished along with the expression of CRs. *Bonferroni-corrected, $p<0.008$.

sons $=0.05$, Bonferonni corrected $\left.\mathrm{p}_{\text {crit }}=0.008\right)$. Persistent and phasic tone cells continued to show significant spike responses relative to baseline (persistent: $n=8$ cells, $t_{(7)}=4.36, p=0.002$; phasic tone: $n=16$ cells $t_{(15)}=4.15, p<0.001$; Figure 8, right bar graph). The results suggest that the spike responses of $\mathrm{mPFC}$ trace cells are driven by feedback from the output pathway of the cerebellum that drives CRs, whereas persistent and phasic tone responses are upstream of the cerebellum.

\section{Time course of the effects of DCN inactivation on mPFC spike activity}

The previous analyses demonstrate the effects of DCN inactivation on mPFC cells based on spike activity that was averaged over trials before and after infusions. A third analysis examined changes in the spike activity of MPFC cells with greater trial-bytrial resolution to test whether the abolition of trace cell activity is abrupt, corresponding to the nearly immediate abolition of CRs. For each trace interval and persistent cell, the spike data from each trial were binned (100 ms), including the $1 \mathrm{~s}$ before and after each trial, creating a 30 (number of time bins per trial) by 108 (number of trials per session) matrix. Each cell's matrix was normalized to its average baseline activity, and the matrix from each cell in each response category was averaged to create a matrix of the mean increase in the number of spikes observed for that response type while conserving the individual trials across sessions (Fig. 9; the matrices of cells from sessions in which rabbits showed a delayed response were aligned accordingly).

The averaged matrix for trace cells suggests that trace interval activity decreased to baseline levels within just a few trials after DCN inactivation, in contrast to the spike activity observed during the second half of control sessions (Fig. 9A). We tested the hypothesis that trace cell activity rapidly abolished to baseline after DCN inactivation by comparing trace interval activity during the second block of trials after infusions, corresponding to the behavioral criteria used to determine complete inactivation (i.e., when $C R$ rate $<15 \%$, see Materials and Methods), versus the same block during control conditions (Fig. 9A, right, block 8). Trace cells showed a significant decrease in activity relative to controls by the second block of trials after infusion ( $n=16$ and 16 cells for DCN and controls, respectively, $t_{(16.44)}=2.64, p=0.018$; Fig. $9 A$ ). Not only was there a significant decrease relative to controls, trace cell responses were decreased to zero by the second block ( $\mathrm{sin}$ gle sample two-tailed test, $\mathrm{H}_{0}$ : mean = $0, n=16$ cells, $\left.t_{(15)}=0.16, p=0.88\right)$, indicating that trace activity was abolished during the very first block in which complete behavioral abolition was observed. There was no difference in trace cell activity between DCN inactivation and control conditions for the block just before infusions $(n=16$ and 16 cells, $t_{(29.74)}=0.03, p=0.97$; Fig. $9 A$, right, block 6). Consistent with previous analyses, no difference was observed between the spike responses of persistent cells during control and DCN inactivation either just before $(n=8$ and 14 cells, $\left.t_{(19.21)}=0.21, p=0.84\right)$ or just after infusions $\left(t_{(20.86)}=0.49, p=0.63\right.$; Fig. $9 B$, right, blocks 6 and 8 , respectively). The data show that trace interval responses were abolished in accordance with the abolition of CRs.

The matrix of averaged spike responses for trace and persistent cells were collapsed across trials for the preinfusion and postinfusion epochs, similar to previous analyses. The same results were observed when analyzed this way, supporting the results of the previous analyses (Fig. 9C,D). For trace cells, the spike response profile during trials was significantly affected by DCN inactivation (postinfusion vs postcontrol: Kolmogorov-Smirnov test, $\mathrm{D}=0.55, p<0.001$; preinfusion comparison: $\mathrm{D}=0.28, p=$ 0.08; Fig. 9C). The spike response profile of persistent cells over the trial was not affected by DCN inactivation (post: $\mathrm{D}=0.25$, $p=0.14$; pre: $\mathrm{D}=0.23, p=0.23$; Fig. $9 D$ ). The results suggest that the spike responses of persistent cells during trace conditioning were unaffected by DCN inactivation throughout the entire trial, in addition to the lack of an effect during the trace interval as demonstrated in previous analyses. In contrast, the average spike response of trace interval cells was significantly affected by the abolition of CRs, further supporting the previous results.

\section{Discussion}

A recent study revealed two patterns of single-unit responses in the $\mathrm{mPFC}$ that in principle would be capable of engaging the cerebellum given that both sufficiently overlap with the US (Siegel et al., 2012). The present results suggest that one pattern, trace interval activity, depends on cerebellar output and therefore reflects feedback to the $\mathrm{mPFC}$ regarding behavioral output. In contrast, persistent responses were unchanged by cerebellar inactivation. Together with previous studies, the results implicate persistent responses as the best candidate input from the mPFC that can bridge the temporal gap between the CS and US, enabling the cerebellum to express trace CRs (Kalmbach et al., 2010, 2011). The results represent the first evidence of CS-evoked activity in the forebrain that overlaps with the timing of the US and that does not reflect CR-associated feedback in the trace conditioning pathway.

Trace interval (CR-associated) activity in the forebrain is feedback from the cerebellar output pathway

The trace interval activity observed in the mPFC during trace eyelid conditioning was abolished to baseline levels during cerebellar inactivation, indicating that such response patterns reflect 
A Trace Cell Activity during DCN Inactivation

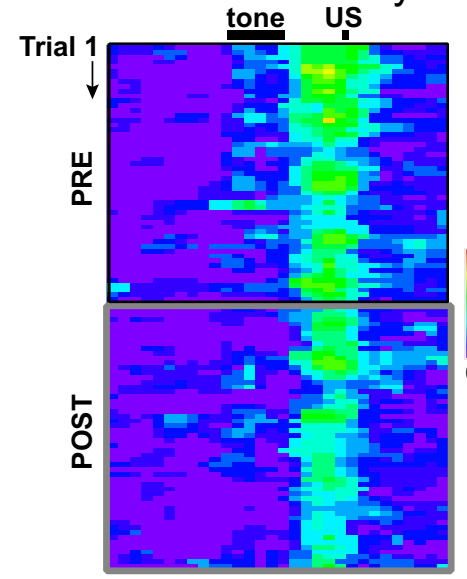

Controls

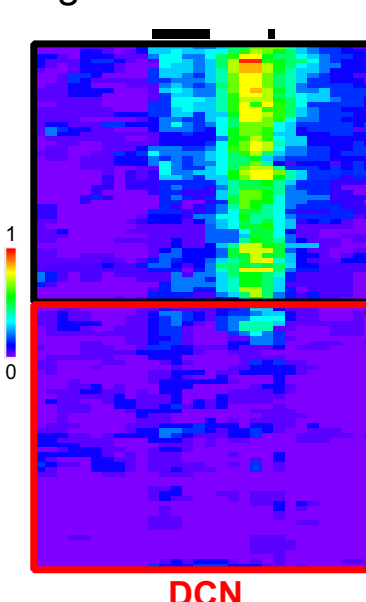

DCN

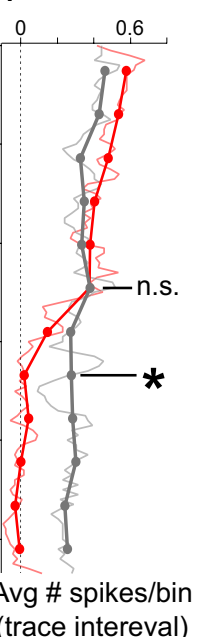

(trace intereval)

\section{Control vs. DCN}
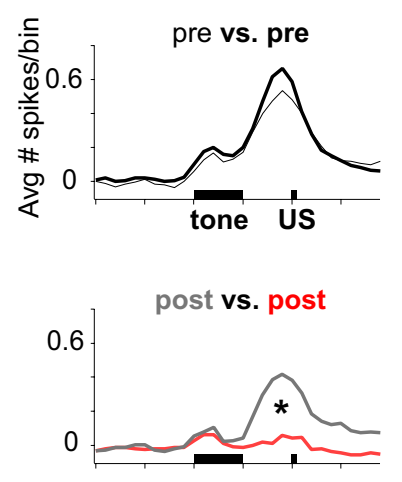

\section{B Persistent Cell Activity during DCN Inactivation}

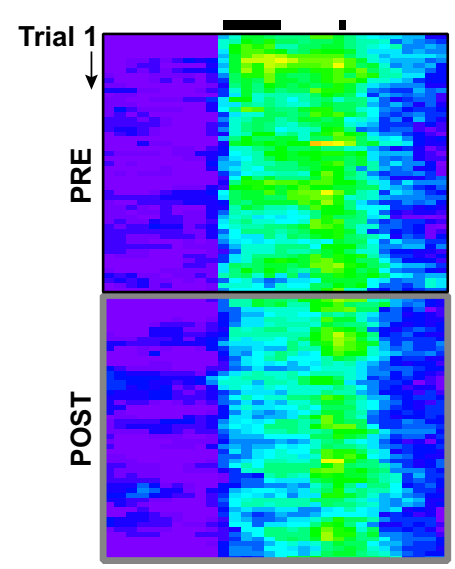

Controls

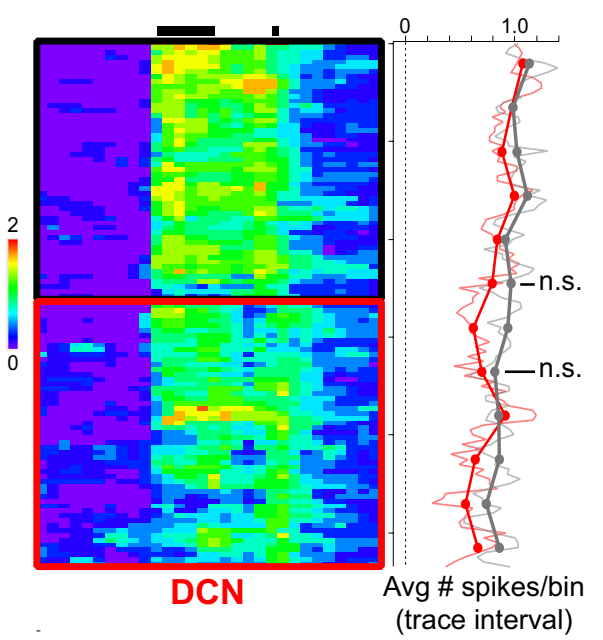

\section{Control vs. DCN}
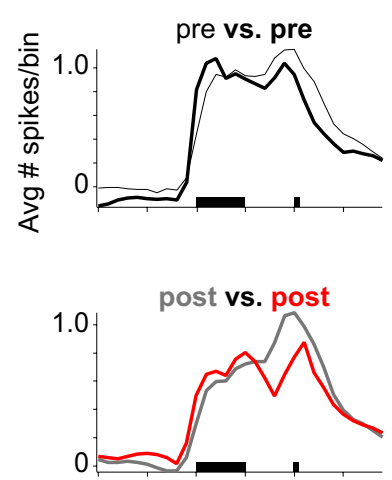

Figure 9. Pseudo-colored raster plots of average increases in activity (number of spikes/100 ms bin $\times$ trial) during sessions for persistent $(\boldsymbol{A})$ and trace interval $(\boldsymbol{B})$ cells recorded during control (left) and DCN infusion sessions (right). Black bars indicate CS and US presentation during trials. $\boldsymbol{A}$, Trace interval cells appeared to show decreased activity within just a few trials after DCN inactivation. Right matrix, red box indicates inactivation epoch. The mean number of spikes observed during the trace interval was averaged for blocks of trials (right) and shows that trace cell activity was abolished to baseline by the second block ( $n=16$ cells, $t=0.16, p=0.88$ relative to baseline). *Significant difference between DCN and controls, $n=16$ and 16 cells, $t=2.64, p=0.018$. $\boldsymbol{B}$, Persistent cells showed gradually decreasing activity over the session, which was not affected by DCN inactivation (right: $n=8$ and 14 cells, $t=0.49, p=0.63$ ). $\boldsymbol{C}$, Temporal profile of mean spike response of trace cells over the entire trial (100 ms bins), averaged across preinfusion (top) or postinfusion (bottom) trials. Black bars indicate presentation of conditioning stimuli. The response profile of trace cells changed significantly during DCN inactivation (Kolmogorov-Smirnov test, $D=0.55,{ }^{*} p<0.001$ ), specifically during the trace interval, US, and post-trial time points, whereas CS responses were similar. D, Temporal profile of mean spike response of persistent cells over the entire trial during preinfusion (top) or postinfusion (bottom) trials. The profile during the postinfusion trials was not significantly different from controls (Kolmogorov-Smirnov test, $D=0.25, p=0.14$ ), suggesting that persistent responses were unaffected by $D C N$ inactivation.

feedback associated with learned behavioral responses. Increased neural activity that is highly correlated with behavioral CRs (i.e., here referred to as trace interval activity) is not unique to the $\mathrm{mPFC}$, nor is it unique to the trace conditioning paradigm. Such activity has also been observed in the hippocampus and medial thalamic nuclei during delay eyelid conditioning (Berger et al., 1976; Halverson et al., 2010). CR-associated activity was first reported for the hippocampus and was initially interpreted as potentially driving learned responses because it appeared just before the first behavioral CRs (Berger et al., 1976). It was surprising then that animals with hippocampal lesions failed to show deficits in learning or expression during delay conditioning, and even more surprising when DCN lesions or inactivation completely abolished the CR-associated hippocampal responses along with the expression of CRs (Clark et al., 1984; Sears and Steinmetz,
1990). A similar test has not been reported for CR-associated thalamic responses or for any other forebrain region. To date, the CR-associated activity commonly observed in forebrain regions has not been shown to be definitively upstream from the cerebellum in any form of eyelid conditioning (Clark et al., 1984, 1997; Sears and Steinmetz, 1990; Halverson et al., 2010; PachecoCalderón et al., 2012). We suggest that any such activity is likely a reflection of cerebellar output and would also be abolished along with CRs, even for forebrain-dependent versions of eyelid conditioning.

Source(s) of feedback that drive CR-associated activity in the forebrain and potential function in the $\mathrm{MPFC}$

The precise source of CR-associated feedback to the mPFC, as reflected in trace interval activity, was not addressed in this study. 
This pattern of spike response could derive from an input from the anterior interpositus DCN to the $\mathrm{mPFC}$ via the thalamus. In cats, rats, and mice, both the dentate and interpositus cerebellar nuclei project to the ventrolateral thalamus (McCrea et al., 1978; Tolbert et al., 1978; Payne, 1983; Allen Mouse Brain Connectivity Atlas). This same region of thalamus projects to the $\mathrm{mPFC}$ in all of these species, as well as in rabbit (Shinoda et al., 1985; Hoover and Vertes, 2007; Oswald et al., 2007; Allen Mouse Brain Connectivity Atlas), suggesting that input to PFC from the DCN is possible via the thalamus. However, the input driving CRassociated activity could also originate from anywhere along the motor output pathway, including the red nucleus (Bernays et al., 1988; Tarnecki, 1988; Ostrowska et al., 1993). Further studies are required to address the precise source(s) of CR-associated activity in the MPFC during trace eyelid conditioning.

Perhaps a more pressing question is exactly what the potential role of behavior-associated feedback to the mPFC network might be. We were unable to detect any consistent effect of DCN inactivation on the activity of persistent cells in the mPFC of trained animals. However, it is likely that these cells also receive behaviorassociated feedback that is somewhat masked by the persistent response. Evidence for this possibility can be seen in Figure $9 B$. PFC neurons showed an apparent decrease in persistent spiking just before the US during DCN inactivation, at the time when a CR would have been observed, which was not observed when CRs were expressed before inactivation. It is possible that this feedback is not important for ongoing expression but may play an important role during other conditions, such as the acquisition of CRs. Berger et al. (1976) observed CR-associated activity in the hippocampus during delay conditioning before the expression of CRs, suggesting that DCN output can drive some downstream activity before the behavioral expression of learning. A potential role for CR-associated feedback to the MPFC during trace conditioning could be to enhance the CS-evoked persistent activity that serves as the cerebellar input to drive learning and CR expression (Halverson et al., 2010; Campolattaro et al., 2011). The increased responsiveness of persistent spike activity in the mPFC could more reliably drive the expression of CRs after the circuit has essentially learned, perhaps as a final phase of acquisition. Determining the source of the CR-associated feedback and blocking those inputs to the mPFC during learning would be an essential test of this proposed function.

\section{CS-evoked persistent responses do not reflect CR- associated feedback}

An important finding of the present study is that mPFC persistent responses were not affected by DCN inactivation and the abolition of CRs and therefore remain a possible source of input from the mPFC to enable the expression of cerebellar learning. Although we do not know whether the persistent mPFC neurons in this study projected to the pons, previous studies suggest that it is likely. First, in vitro work has shown that corticopontine projecting $\mathrm{MPFC}$ cells displayed persistent spike activity to phasic stimuli with activation of cholinergic or metabotropic glutamate receptors, whereas cells with commissural projections were far less likely to spike persistently under any condition (Dembrow et al., 2010; Kalmbach et al., 2013). Second, injection of anterograde tracer in the region of $\mathrm{mPFC}$, where persistent responses were observed in response to conditioning stimuli, resulted in labeled axons in specific pontine regions in which cells also responded persistently (Siegel et al., 2012). It has been shown that a persistent input, via direct stimulation of pontine inputs to the cerebellum, in combination with a separate tone-like stimulation pattern is sufficient to engage cerebellar learning and the expression of CRs, which are indistinguishable from animals trained with a tone CS (Kalmbach et al., 2010, 2011).

CS-evoked persistent responses in the $\mathrm{MPFC}$ have been reported in diverse species during performance of different tasks that share the common feature of a stimulus-free interval between CS presentation and behavioral response (Fuster, 1973; Goldman-Rakic, 1995; Gilmartin and McEchron, 2005; Takehara-Nishiuchi and Mcnaughton, 2008; Burgos-Robles et al., 2009; Siegel et al., 2012). The mPFC shows a high degree of reciprocity with the motor output systems engaged in many of these tasks, most notably the basal ganglia and/or primary motor cortex. Because trace eyelid conditioning engages the cerebellum, we were able to pharmacologically block the motor response output at or before feedback to upstream brain regions could occur, at the DCN. Persistent activity in the mPFC during trace eyelid conditioning was not abolished with DCN inactivation and therefore cannot reflect cerebellar feedback to the forebrain. It is unlikely that such activity reflects a persistent input to the mPFC from another brain region because previous studies failed to observe persistent response patterns in the superficial input layers (Weible et al., 2003; Siegel et al., 2012). Together, the data support the hypothesis that the mPFC supports trace eyelid conditioning by generating a persistently active input to the cerebellum, via the pons, that bridges the temporal gap between the CS and US to allow the cerebellar network to express well-timed learned responses.

It is currently unknown whether persistent responses in the $\mathrm{mPFC}$ are acquired with training or whether such responses represent an inherent property of how some mPFC cells respond to stimuli. The hippocampus has been implicated specifically in the acquisition of trace CRs but is not necessary for the ongoing expression of learned responses (Kim et al., 1995; Takehara et al., 2003). Although the precise role of the hippocampus in trace eyelid conditioning remains unclear, at least one study briefly described a persistent-like response during trace conditioning that was observed early in training in hippocampal cells, which was no longer present as the rabbits acquired CRs (Solomon et al., 1986). It is possible that hippocampal inputs may facilitate persistent spike responses in the $\mathrm{MPFC}$ at the earliest stages of learning, either by providing a CS-evoked persistent input or by facilitating synapses by providing additional input that is coincident with other CS inputs (e.g., Laroche et al., 1990). Further studies will be required to explore these hypotheses and the nature of hippocampal-prefrontal interactions during trace conditioning.

\section{References}

Allen MouseBrain ConnectivityAtlas (2013) http://connectivity.brain-map. org/.

Berger TW, Alger B, Thompson RF (1976) Neuronal substrate of classical conditioning in the hippocampus. Science 192:483-485. CrossRef Medline

Bernays RL, Heeb L, Cuenod M, Streit P (1988) Afferents to the rat red nucleus studied by means of $\mathrm{D}-\left[{ }^{3} \mathrm{H}\right]$ aspartate, $\left[{ }^{3} \mathrm{H}\right]$ choline and nonselective tracers. Neuroscience 26:601-619. CrossRef Medline

Burgos-Robles A, Vidal-Gonzalez I, Quirk GJ (2009) Sustained conditioned responses in prelimbic prefrontal neurons are correlated with fear expression and extinction failure. J Neurosci 29:8474-8482. CrossRef Medline

Campolattaro MM, Kashef A, Lee I, Freeman JH (2011) Neuronal correlates of cross-modal transfer in the cerebellum and pontine nuclei. J Neurosci 31:4051-4062. CrossRef Medline

Clark GA, McCormick DA, Lavond DG, Thompson RF (1984) Effects of lesions of cerebellar nuclei on conditioned behavioral and hippocampal neuronal responses. Brain Res 291:125-136. CrossRef Medline 
Clark RE, Gohl EB, Lavond DG (1997) The learning-related activity that develops in the pontine nuclei during classical eye-blink conditioning is dependent on the interpositus nucleus. Learn Mem 3:532-544. CrossRef Medline

Dembrow NC, Chitwood RA, Johnston D (2010) Projection-specific neuromodulation of medial prefrontal cortex neurons. J Neurosci 30: 16922-16937. CrossRef Medline

Dilgen J, Tejeda HA, O’Donnell P (2013) Amygdala inputs drive feedforward inhibition in the medial prefrontal cortex. J Neurophysiol 110:221-229. CrossRef Medline

Fuster JM (1973) Unit activity in prefrontal cortex during delayed-response performance: neuronal correlates of transient memory. J Neurophysiol 36:61-78. Medline

Gilmartin MR, McEchron MD (2005) Single neurons in the medial prefrontal cortex of the rat exhibit tonic and phasic coding during trace fear conditioning. Behav Neurosci 119:1496-1510. CrossRef Medline

Goldman-Rakic PS (1995) Cellular basis of working memory. Neuron 14: 477-485. CrossRef Medline

Halverson HE, Lee I, Freeman JH (2010) Associative plasticity in the medial auditory thalamus and cerebellar interpositus nucleus during eyeblink conditioning. J Neurosci 30:8787-8796. CrossRef Medline

Hoover WB, Vertes RP (2007) Anatomical analysis of afferent projections to the medial prefrontal cortex in the rat. Brain Struct Funct 212:149-179. CrossRef Medline

Ito M, Sakurai M, Tongroach P (1982) Climbing fibre induced depression of both mossy fibre responsiveness and glutamate sensitivity of cerebellar Purkinje cells. J Physiol 324:113-134. Medline

Kalmbach BE, Ohyama T, Kreider JC, Riusech F, Mauk MD (2009) Interactions between prefrontal cortex and cerebellum revealed by trace eyelid conditioning. Learn Mem 16:86-95. CrossRef Medline

Kalmbach BE, Ohyama T, Mauk MD (2010) Temporal patterns of inputs to cerebellum necessary and sufficient for trace eyelid conditioning. J Neurophysiol 104:627-640. CrossRef Medline

Kalmbach BE, Voicu H, Ohyama T, Mauk MD (2011) A subtraction mechanism of temporal coding in cerebellar cortex. J Neurosci 31:2025-2034. CrossRef Medline

Kalmbach BE, Chitwood RA, Dembrow NC, Johnston D (2013) Dendritic generation of mGluR-mediated slow afterdepolarization in layer 5 neurons of the prefrontal cortex. J Neurosci 33:13518-13532. CrossRef Medline

Kim JJ, Clark RE, Thompson RF (1995) Hippocampectomy impairs the memory of recently, but not remotely, acquired trace eyeblink conditioned responses. Behav Neurosci 109:195-203. CrossRef Medline

Kronforst-Collins MA, Disterhoft JF (1998) Lesions of the caudal area of rabbit medial prefrontal cortex impair trace eyeblink conditioning. Neurobiol Learn Mem 69:147-162. CrossRef Medline

Laroche S, Jay TM, Thierry AM (1990) Long-term potentiation in the prefrontal cortex following stimulation of the hippocampal CA1/subicular region. Neurosci Lett 114:184-190. CrossRef Medline

Mauk MD, Donegan NH (1997) A model of Pavlovian eyelid conditioning based on the synaptic organization of the cerebellum. Learn Mem 4:130158. CrossRef Medline

McCrea RA, Bishop GA, Kitai ST (1978) Morphological and electrophysiological characteristics of projection neurons in the nucleus interpositus of the cat cerebellum. J Comp Neurol 181:397-419. CrossRef Medline

Ostrowska A, Sikora E, Mierzejewska-Krzyzowska B, Zimny R (1993) The dentatorubral projection in the rabbit with emphasis on distinc- tion from the interpositorubral connectivity: an HRP retrograde tracer study. J Hirnforsch 34:9-23. Medline

Oswald BB, Knuckley B, Maddox SA, Powell DA (2007) Ibotenic acid lesions to ventrolateral thalamic nuclei disrupt trace and delay eyeblink conditioning in rabbits. Behav Brain Res 179:111-117. CrossRef Medline

Pacheco-Calderón R, Carretero-Guillén A, Delgado-García JM, Gruart A (2012) Red nucleus neurons actively contribute to the acquisition of classically conditioned eyelid responses in rabbits. J Neurosci 32: 12129-12143. CrossRef Medline

Payne JN (1983) The cerebellar nucleo-cortical projection in the rat studied by the retrograde fluorescent double-labelling method. Brain Res 271: 141-144. CrossRef Medline

Sears LL, Steinmetz JE (1990) Acquisition of classically conditioned-related activity in the hippocampus is affected by lesions of the cerebellar interpositus nucleus. Behav Neurosci 104:681-692. CrossRef Medline

Shinoda Y, Futami T, Kano M (1985) Synaptic organization of the cerebello-thalamo-cerebral pathway in the cat: II. Input-output organization of single thalamocortical neurons in the ventrolateral thalamus. Neurosci Res 2:157-180. CrossRef Medline

Siegel JJ, Neunuebel JP, Knierim JJ (2008) Dominance of the proximal coordinate frame in determining the locations of hippocampal place cell activity during navigation. J Neurophysiol 99:60-76. CrossRef Medline

Siegel JJ, Kalmbach B, Chitwood RA, Mauk MD (2012) Persistent activity in a cortical-to-subcortical circuit: bridging the temporal gap in trace eyelid conditioning. J Neurophysiol 107:50-64. CrossRef Medline

Solomon PR, Vander Schaaf ER, Thompson RF, Weisz DJ (1986) Hippocampus and trace conditioning of the rabbit's classically conditioned nictitating membrane response. Behav Neurosci 100:729-744. CrossRef Medline

Takehara K, Kawahara S, Kirino Y (2003) Time-dependent reorganization of the brain components underlying memory retention in trace eyeblink conditioning. J Neurosci 23:9897-9905. Medline

Takehara-Nishiuchi K, McNaughton BL (2008) Spontaneous changes of neocortical code for associative memory during consolidation. Science 322:960-963. CrossRef Medline

Tarnecki R (1988) Functional connections between neurons of interpositus nucleus of the cerebellum and the red nucleus. Behav Brain Res 28: 117-125. CrossRef Medline

Tierney PL, Dégenètais E, Thierry AM, Glowinski J, Gioanni Y (2004) Influence of the hippocampus on interneurons of the rat prefrontal cortex. Eur J Neurosci 20:514-524. CrossRef Medline

Tolbert DL, Bantli H, Bloedel JR (1978) Multiple branching of cerebellar efferent projections in cats. Exp Brain Res 31:305-316. Medline

Tseng KY, Mallet N, Toreson KL, Le Moine C, Gonon F, O’Donnell P (2006) Excitatory response of prefrontal cortical fast-spiking interneurons to ventral tegmental area stimulation in vivo. Synapse 59:412-417. CrossRef Medline

Weible AP, Weiss C, Disterhoft JF (2003) Activity profiles of single neurons in caudal anterior cingulate cortex during trace eyeblink conditioning in the rabbit. J Neurophysiol 90:599-612. CrossRef Medline

Weible AP, Weiss C, Disterhoft JF (2007) Connections of the caudal anterior cingulate cortex in rabbit: neural circuitry participating in the acquisition of trace eyeblink conditioning. Neuroscience 145:288-302. CrossRef Medline

Weiss C, Disterhoft JF (1996) Eyeblink conditioning, motor control, and the analysis of limbic-cerebellar interactions. Behav Brain Sci 19:479481 . 